\title{
EL JURÁSICO MEDIO DE LA CUENCA CATALANA: UNIDADES LITOESTRATIGRÁFICAS Y ELEMENTOS PALEOGEOGRÁFICOS
}

\author{
Sixto FERNÁNDEZ-LÓPEZ1, Marcos AURELL2, Fernando GARCÍA \\ JORAL', Juan José GÓMEZ3, María Helena Paiva HENRIQUES ${ }^{5}$, \\ Gemma MARTÍNEZ', Guillermo MELÉNDEZ y Luis Carlos SUÁREZ \\ $V E G A^{3}$

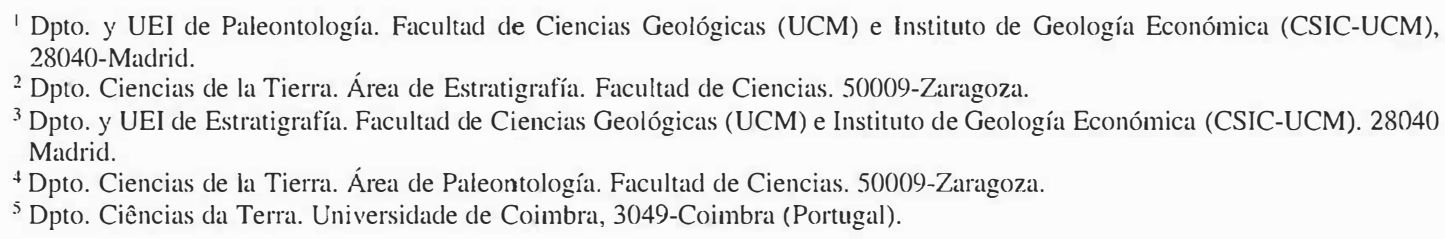

Fernández-López, S., Aurell, M., García Joral, F., Gómez, J.J., Henriques, M.H.P., Martínez, G., Meléndez, G. y Suárez Vega, L.C. 1996. El Jurásico Medio de la Cuenca Catalana: unidades litoestratigráficas y elementos paleogeográficos. [The Middle Jurassic of the Catalan Basin: lithostratigraphic units and paleogeographic elements]. Revista Española de Paleontología, $\mathbf{N}^{\circ}$ Extraordinario, 122-139. ISSN 0213-6937.

\begin{abstract}
The palaeogeography and facies distribution of the Catalan Basin during the Middle Jurassic are reconstructed, on the basis of outcrops and logs data. A new lithostratigraphic classification valid for the Catalan Basin is defined and its equivalence with the correlative units in the Iberian Basin and Majorca is discussed. A system of arched, listric-shaped faults dipping towards the mediterranean sea was a major factor determining the differentiation of the subsident Platform of Tortosa. From a palaeobiogeographical point of view, the ammonite and brachiopod recorded associations from the Platform of Tortosa are taxonomically similar to the associations of the epicontinental european basins. The Catalan Basin and Majorca were two geographically separate areas, maintaining separate biogeographical and taphonomic dispersal ways in the Middle Jurassic. Yet in the Catalan Basin expanded, outer shelf sections were developed during the Garantiana Biochron (Upper Bajocian). During this episode the basin reached the maximum bathymetric values and acted as a biogeographical dispersal area for some taxonomic groups characteristic of the West-Tethys.
\end{abstract}

Keywords: lithostratigraphy, biostratigraphy, palaeogeography, palaeobiogeography, ammonites, brachiopods, taphonomic condensation, stratigraphic condensation, Iberian Basin, Majorca, basin analysis.

\section{RESUMEN}

Se reconstruyen las variaciones de facies y la configuración paleogeográfica de la Cuenca Catalana durante el Jurásico Medio, a partir de los datos obtenidos en afloramientos y sondeos. Se propone un nuevo sistema de unidades litoestratigráficas, válido para la Cuenca Catalana, y se analizan sus equivalencias con las unidades identificadas en la Cordillera Ibérica y en Mallorca. Un sistema de fallas arqueadas, con trazado lístrico y con sentido descendente hacia el Mediterráneo, debió contribuir a la diferenciación de la Plataforma subsidente de Tortosa. Desde el punto de vista paleobiogeográfico destacan las semejanzas taxonómicas que muestran las asociaciones registradas de ammonites y braquiópodos en la Plataforma de Tortosa respecto a las de otras cuencas epicontinentales europeas. La Cuenca Catalana y Mallorca debieron ser dos dominios geográficamente separados y aislados uno de otro, con vías de dispersión biogeográfica y tafonómica diferentes, durante el Jurásico Medio. En la Cuenca Catalana se desarrollaron secciones expandidas en facies de plataforma abierta durante el Biocrón Garantiana (Bajociense Superior), cuando la cuenca alcanzó los valores batimétricos máximos y actuó como un área de expansión biogeográfïca para algunos grupos taxonómicos característicos del Tethys occidental.

Palabras clave: litoestratigrafía, bioestratigrafía, paleogeografía, paleobiogeografía, ammonites, braquiópodos, condensación tafonómica, condensación estratigráfica, Cuenca Ibérica, Mallorca, análisis de cuencas.

\section{INTRODUCCIÓN}

Entre los primeros trabajos referentes al Jurásico Medio de la provincia de Tarragona cabe destacar el de Killian y Fallot (1920), en el que se da a conocer la presencia y las facies de varios pisos jurásicos teniendo en cuenta los fósiles encontrados por Almera, Faura y Sans, Bataller y Villaseca durante las investigaciones realizadas por el Servicio del Mapa Geológico de Cataluña, en los yacimientos de Cap de Salou, Sierra de Tivissa, Mas Ramé, Cardó, Tivenys y Tortosa. Estos dos autores indican que los braquiópodos encontrados en materiales del Lías corresponden a la "facies española" de Choffat (1880); las facies de cefalópodos bajocienses contienen ammonoideos de Suabia y de Nor- 
mandía junto a tipos mediterráneos de los Alpes Meridionales; y, si bien cerca de Tortosa el Bathoniense muestra su facies de cefalópodos, un episodio nerítico bathoniense con braquiópodos que recuerdan a los de tipo jurásico está presente en la parte superior del yacimiento de Cap de Salou.

Los primeros cortes detallados del Jurásico Medio de la provincia de Tarragona fueron publicados por Faura y Sans, Fallot y Bataller (1921). Más tarde, Bataller (1922, 1926) presenta el estado de los conocimientos regionales referentes al Jurásico y cita las localidades donde ha encontrado fósiles de los distintos pisos del Jurásico Medio: Cap de Salou, Vandellòs (Serra dels Dedals), Campçanes (Mas Ramé), Tivissa (Ermita de Sant Blai), Cardó, Tivenys (km. 16-18 de la carretera Tivenys-Benifallet, Coll de l'Argila, Coll de Soms), Paüls (Coll de Pousec), Mont Caro (Coll del Caregol), Alfara (Serra de Les Feixes, Maraco), El Toscá (Les Foyes), l'Embarronat y Font de Carlades que se aproxima al yacimiento de Birmensdorf por los espongiarios.

Fallot y Blanchet (1923) publicaron una monografía paleontológica de los taxones identificados entre los fósiles jurásicos de esta región. Estos autores distinguen sobre los materiales del Lías superior que contienen abundantes restos de braquiópodos, belemnites y lamelibranquios: algunos materiales aalenienses (con fósiles procedentes de Prat de Compte y Tivenys); margas y margocalizas bajocienses (Tivenys, Cardó, Mas Ramé, Tivissa, Mas Riudoms); calizas y dolomías bathonienses (Tivissa, Serra dels Dedals, Cap de Salou); calizas callovienses (Cap de Salou); y materiales oxfordienses (Font de Carlades). Fallot y Blanchet (op. cit.) consideran que los materiales jurásicos de la provincia de Tarragona forman parte de la Cuenca Aragonesa o del "Golfo Aragonés". Según su interpretación, un mar epicontinental ocupaba la zona comprendida entre la Meseta y la región pirenaica y comunicaba por el dominio cantábrico con el mar situado al oeste de Europa durante el Jurásico Medio. A partir del Calloviense este mar epicontinental quedó reducido a un golfo de orientación NW-SE, que era tributario de las zonas de alta mar cuyo límite pasaba al sur de las Baleares; este golfo también debió de estar en relación directa con las regiones del SE de Francia y con las regiones alpinas.

Dubar (1925) indica que los braquiópodos encontrados por Bataller en la provincia de Tarragona, en calizas con nódulos de sílex, se aproximan mucho más a los de la región de Var (facies provenzal) que a los de Pirineos (facies jurásica).

Las características geológicas regionales de la Cordillera Costero-Catalana fueron expuestas por Llopis Lladó en los mapas geológicos de síntesis a escala 1/200.000 publicados en 1942 y más tarde en su tesis doctoral (1943).

Bulard (1972) destaca que solamente en el extremo SW de los Catalánides hay formaciones del Jurásico Medio; al norte de Reus, los materiales jurásicos más recientes no sobrepasan el Lías, al haber sido erosionados los términos suprayacentes. Este autor describe e interpreta, a escala de piso, los materiales jurásicos que afloran al sur de la Cordillera Costero-Catalana (Tivenys, Cardó, Tivissa, Vandellòs, Mas Riudoms, Llabería, Cap de Salou), en los Puertos de Beceite (Río Matarranya, Río Pena, Las Vuellas, Masía de San Miguel, Mina Maruja, l'Embarronat, El Caregol y Alfara) y entre el Río Pena y el Río Guadalopillo (Ráfales, La Cañada de Verich y Calanda). En sus conclusiones, Bulard (op. cit.) propone diferenciar una "Provincia catalana" de una "Provincia ibérica", porque la primera presenta una sucesión un poco diferente de la desarrollada en la Cordillera Ibérica; en particular, la "Provincia catalana" presenta calizas bioclásticas toarcienses seguidas de una potente serie monótona (más de 100 metros) de margas y margo-calizas del Bajociense medio y superior que comienza con niveles condensados y continúa con calizas de filamentos a menudo dolomitizadas ( 25 a 30 metros bathonienses y una treintena de metros callovienses), y esta provincia quizás representa unas condiciones batimétricas más importantes al estar en las proximidades de la Mesogea.

La publicación de la información obtenida a partir de sondeos petrolíferos (Stoeckinger, 1976; Lanaja, 1987) proporcionó nuevos datos para interpretar los materiales del Dogger más allá de los límites de la línea de costa actual, asî como la comunicación entre la Cuenca Ibérica y la Cuenca Pirenaica Meridional, y la existencia de un Macizo Catalán durante el Jurásico Medio.

A partir de 1980 comenzaron a publicarse los mapas geológicos a escala 1/50.000, permitiendo conocer con mayor precisión la distribución geográfica de los afloramientos de materiales del Dogger (cf. Núñez et al., 1980; Orche et al., 1980a, 1980b; Barnolas et al., 1985; Barnolas y Simó, 1985; Giner Sánchez y Simó, 1985, 1987).

Según Giner (1980) la desintegración de la plataforma que tiene lugar en el tránsito Lías-Dogger provocó un cambio muy brusco de los elementos paleogeográficos. Este autor distingue tres dominios: el Dominio Ibérico, caracterizado por un Dogger calcáreo poco potente, que corresponde a una plataforma marina hemipelágica con períodos de no-deposición de amplitud muy variable; el Dominio Catalán, que presenta un Dogger muy potente con dos unidades bien diferenciadas (1, margas y margocalizas; 2, calizas micríticas bien estratificadas); y el Dominio del Maestrazgo, donde el Dogger está dolomitizado y erosionado. En el Dominio Catalán desaparece la plataforma somera del Lías y se establece una cuenca profunda (Cuenca Catalana) donde se acumulan los máximos espesores del Dogger en facies pelágicas de plataforma externa sin discontinuidades claras en la sedimentación.

Cadillac et al. (1981, 1985) y Canerot et al. (1984, 1985) exponen de forma sucinta las variaciones sedimentológicas y paleogeográficas del dominio ibérico oriental, proponen nuevas unidades litoestratigráficas para los materiales del Jurásico Medio, y distinguen una "Cuenca de Tortosa" diferenciada durante el Toarciense y el Bajociense al norte de la "Plataforma del Maestrazgo" y al sur de la "Plataforma Catalana".

Anadón et al. (1982) presentan una síntesis sobre la evolución tectónica y estratigráfica de los Catalánides. La cuenca mesozoica catalana es contemplada como la continuación nororiental de la plataforma prebética. Respecto al Jurásico Medio, dichos autores distinguen un dominio meridional (Perelló, Ulldecona, Salou-Tarragona, Llabería) de un dominio central (Garraf, Montmell-Salomó, Alt Gaià). La plataforma desarrollada durante el Lías en el ámbito de los Catalánides muestra una diversificación de facies y una subsidencia diferencial a partir del Pliensbachiense inferior cuando cambia la evolución tectonoestratigráfica de los distintos dominios. El dominio meridional presenta facies de plataforma externa y profunda, con una potente serie de mar- 
gocalizas y margas con ammonites y Zoophycos en la base que se superponen a un nivel de condensación aaleniense. En el dominio central se encuentran facies mucho más someras, dolomíticas, y de menor potencia.

Fernández López y Mouterde (1985) describen las unidades representadas en varias columnas estratigráficas e interpretan, desde el punto de vista tafonómico y paleoecológico, las sucesivas asociaciones de ammonites toarcienses, aalenienses, bajocienses y bathonienses encontradas en la región de Tivenys-Sierra de Cardó, concluyendo que corresponden a formas características de los mares epicontinentales del NW de Europa y que las influencias mesogeas fueron mínimas en esta región.

Salas $(1989,1991)$ presenta una síntesis de las unidades estratigráficas del Jurásico del borde oriental de Iberia. Salas y Casas (1993) distinguen cuatro secuencias deposicionales desde el Aaleniense hasta el Oxfordiense y una zona de umbral que denominan Alto de Tarragona, indicando que las áreas continentales corresponderían a la Meseta y que las aguas marinas más abiertas se establecerían hacia el SE durante el Lías y Dogger. En dicho trabajo y en el de Roca et al. (1994) se trata la tectónica extensiva mesozoica a nivel regional y se expone una reconstrucción paleogeográfica de esta región durante el Jurásico Superior.

La sedimentación jurásica en la Cuenca Catalana parece haber estado controlada por fracturas del basamento, y este control es más evidente durante el Jurásico Superior y el Cretácico Inferior. Estas fracturas formaron parte de mecanismos tectónicos que originaron cambios relativos del nivel del mar así como el crecimiento y la diferenciación de varias plataformas carbonáticas. Sin embargo, los datos bioestratigráficos regionales a escala zonal todavía son muy escasos en lo que respecta a los materiales del Dogger. El estudio a escala zonal de más de 30 cortes realizados en los materiales del Jurásico Medio que afloran en la zona de entronque entre la Cordillera Costero-Catalana y la Cordillera Ibérica (Fig. 1), así como de los datos proporcionados por más de 30 sondeos petrolíferos, nos han permitido reconstruir la configuración paleogeográfica de esta región durante el Jurásico Medio (Fernández-López et al., 1994).

Los objetivos principales del presente trabajo son proponer un sistema de unidades litoestratigráficas válido para la Cuenca Catalana e identificar los principales elementos paleogeográficos de esta cuenca durante el Jurásico Medio.

\section{UNIDADES LITOESTRATIGRÁFICAS}

Entre los materiales jurásicos que han rellenado la Cuenca Catalana no han podido ser reconocidas algunas de las unidades litoestratigráficas utilizadas en la Cuenca Ibérica. Por ejemplo, no ha podido ser identificada la Formación

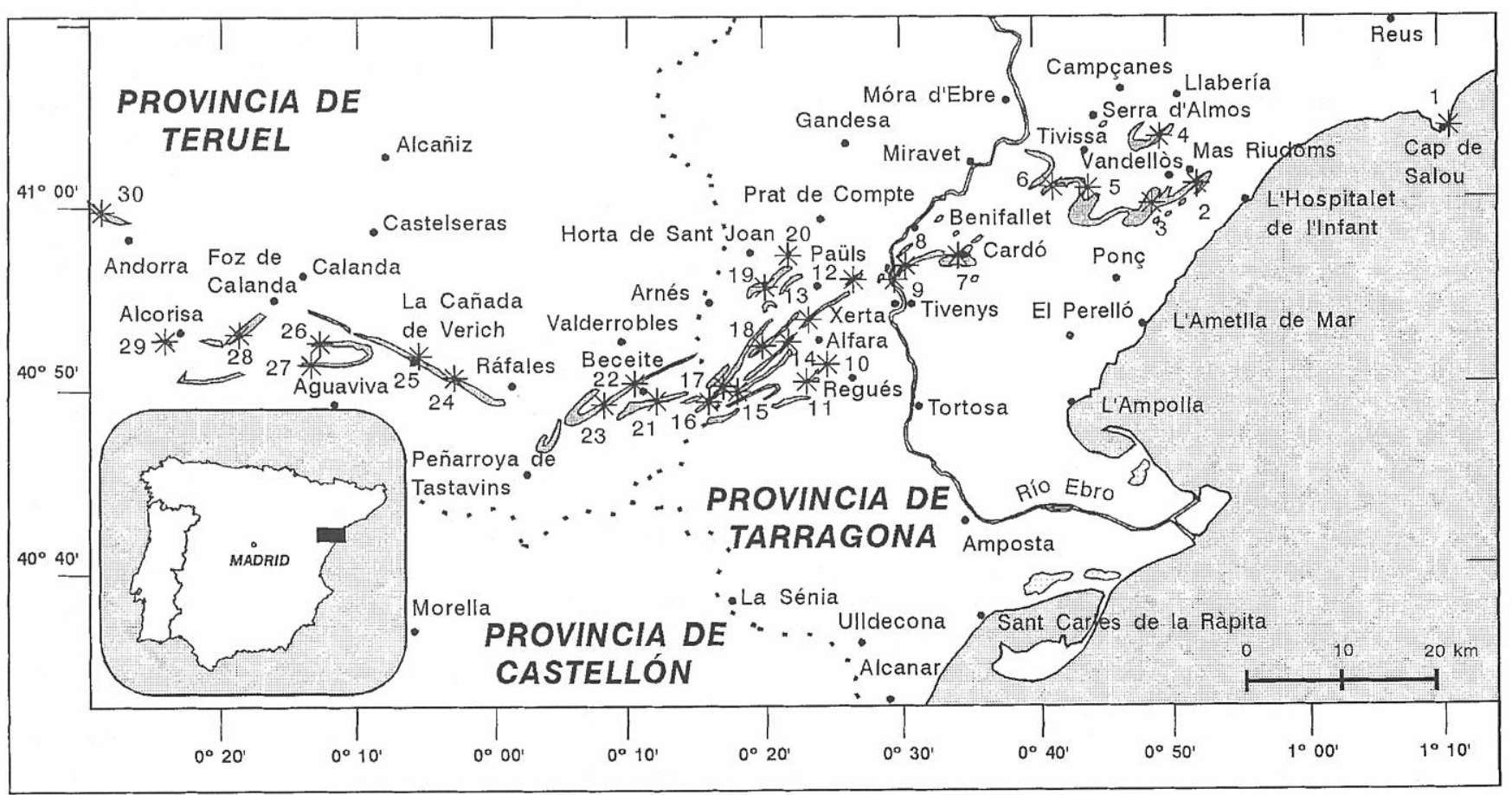

Figura 1. Distribución geográfica de los principales afloramientos de Jurásico Medio en la zona de entronque entre la Cordillera CosteroCatalana y la Cordillera Ibérica, en el límite entre las provincias de Tarragona, Castellón y Teruel. Las localidades donde han sido estudiadas secciones o columnas estratigráficas están indicadas con un asterisco y un número: 1. Cap. de Salou; 2. Mas Riudoms (Espelta); 3. Valdellòs (Puntaire); 4. Llabería (km 36, Bco. de Romultá); 5. Tivissa (La Tossa, La Creu); 6. Tivissa (Mas de Rojals); 7. Cardó; 8. Tivenys (Coll de l’Argila, Km 18, Pedrera de Borrás, km 16,5, Vall Llarga); 9. Tivenys (Pedrera de Julián, Punta de Soms, L’Assut); 10. Alfara; 11. Mont Caro (Coll del Caregol); 12. Xerta-Paüls (km 5; Coll del Musu); 13. Coscollosa (Coll de Pousec); 14. Espina; 15. Carlades-L'Embarronat; 16. Barranco de Millés; 17. Barranco del Grevolar; 18. Río de Estrets; 19. Barranco de Avellanar; 20. Engrillo; 21. Les Voltes; 22. Beceite; 23. Río Pena; 24. Ráfales (Lobatera); 25. La Cañada de Verich; 26. Calanda (Masada del Diablo); 27. Mas de las Matas (Masía Nueva); 28. Alcorisa (km 54,5); 29. Embalse de Gallipuén; 30 . Andorra. 
Alternancia de margas y calizas de Turmiel ni la Formación Carbonatada de Chelva, que comprenden materiales del Lías superior, del Dogger y parte del Malm en la Cuenca Ibérica (Goy et al., 1976; Gómez, 1979; Gómez y Goy, 1979). Por esta razón es conveniente establecer un sistema de unidades litoestratigráficas que sea válido para la Cuenca Catalana.

Como carácter diferencial de la Cuenca Catalana, sobre la Formación Calizas bioclásticas de Barahona se disponen los materiales de tres unidades litoestratigráficas sucesivas que de base a techo son: Formación Calizas y calizas margosas de Sant Blai, Formación Margas de Cardó y Formación Calizas y dolomías de La Tossa (Fig. 2). Los límites de estas unidades pueden ser fácilmente trazados en las fotografías aéreas, aunque los materiales de la Fm. Sant Blai y en especial los de la Fm. Cardó suelen estar cubiertos por derrubios y vegetación porque son los menos competentes y resistentes a la erosión. Sobre la última unidad del Jurásico Medio, la Fm. La Tossa, se encuentran los materiales oxfordienses que llegan a sobrepasar $40 \mathrm{~m}$ de espesor y han sido atribuidos por algunos autores al Miembro Serra de la Creu (Salas, 1987, 1989; Aurell, 1990).

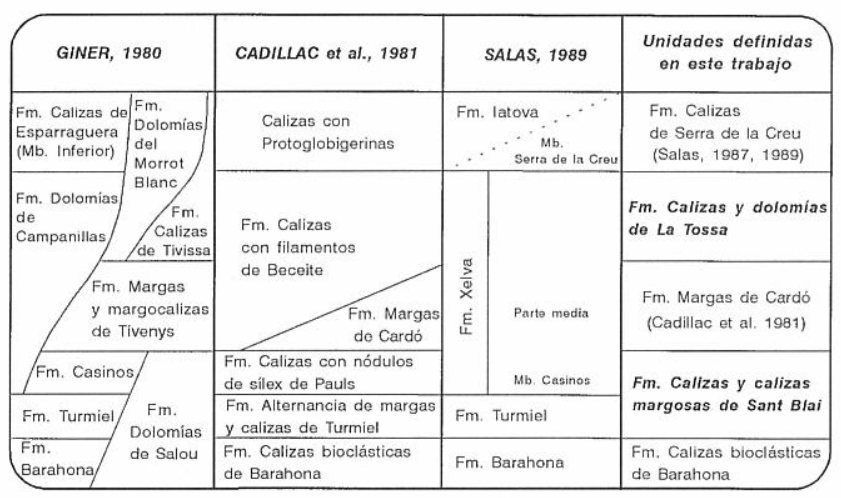

Figura 2. Equivalencias entre las unidades litoestratigráficas utilizadas en algunos trabajos anteriores y las unidades propuestas en el presente trabajo para la Cuenca Catalana.

\section{Formación Calizas y calizas margosas de Sant Blai}

Sobre las calizas bioclásticas de la Fm. Barahona se disponen las calizas y calizas margosas de la Fm. Sant Blai (Fig. 3). El corte tipo de la formación está en el desmonte de la pista que se dirige desde Tivissa hacia el cerro Vista Bella, pasando por la Ermita de Sant Blai, a unos 2,5 km al SW de dicha población y a unos $150 \mathrm{~m}$ al SW de Mas de Rojals, en el término municipal de Tivissa, Hoja del MTN 32-18 (471), siendo sus coordenadas geográficas: $41^{\circ} 01$ '38' ' y 042'38',

En el corte tipo, la Fm. Sant Blai tiene unos $55 \mathrm{~m}$ de espesor y está constituida por calizas mudstone a wackestone, a veces wackestone bioclásticas, entre las que se intercalan delgados niveles de margas y calizas margosas. De base a techo se distinguen tres tramos. Un tramo inferior, de unos 3,8 $\mathrm{m}$ de potencia, constituido por margas y calizas que en la parte superior pasan a calizas wackestone con oolitos ferruginosos. Un tramo intermedio, de unos $23 \mathrm{~m}$ de espesor, compuesto por calizas wackestone bioclásticas con delgadas intercalaciones margosas, localmente con nódulos de sílex, que en los últimos 1,7 m contiene ooides y oolitos ferruginosos, asociados a niveles de removilización con lito- y bioclastos abundantes, a veces fosfáticos, así como superficies de estratificación con perforaciones biogénicas. Un tramo superior, de unos $28 \mathrm{~m}$ de espesor, constituido por calizas mudstone con intercalaciones margosas.

Los materiales de esta unidad se organizan en secuencias estrato- y granocrecientes, de espesor métrico; a excepción de algunas secuencias estrato- y granodecrecientes desarrolladas en el tramo superior, como se observa en las regiones de Tivissa, Vandellòs y Llabería. Las superficies de estratificación suelen ser onduladas o irregulares, y las capas tienen a menudo aspecto noduloso o escasa continuidad lateral. Las estructuras de bioturbación son abundantes en los materiales de esta formación, en particular Zoophycos y Thalassinoides. Los restos de ammonites, belemnites y de organismos bentónicos (lamelibranquios, braquiópodos, crinoideos, serpúlidos, gasterópodos, corales ahermatípicos, briozoarios) son frecuentes en los tramos inferior y medio; en la parte superior de éste último, asociados a las facies de ooides y oolitos ferruginosos, también son frecuentes los restos de espongiarios y localmente se encuentran restos vegetales flotados y restos óseos fragmentados. En el tramo superior, los fósiles son más escasos y los restos de ammonites predominan sobre los de otros grupos taxonómicos, a excepción de Bositra que localmente es abundante.

Los límites inferior y superior de la Fm. Sant Blai suelen ser netos, al estar marcados por substratos endurecidos, con perforaciones biogénicas y costras ferruginosas. La Fm. Sant Blai puede diferenciarse claramente tanto de la unidad que se dispone por debajo como de la unidad superior (Fig. 3). La Fm. Calizas bioclásticas de Barahona presenta facies de calizas packstone a wackestone en las que los bioclastos de bivalvos, braquiópodos, ostréidos y equinodermos, entre otros, suelen ser mucho más abundantes que en la Fm. Sant Blai.

La Fm. Sant Blai ha sido reconocida en Cap de Salou, Llabería, Vandellòs, Tivissa, Sierra de Cardó, Tivenys, así como en las regiones de Xerta-Paüls, Mont Caro (Coll del Caregol), Alfara y Horta de Sant Joan (Engrillo, Barranco del Avellanar, Río de Estrets); sin embargo, los tres tramos diferenciados en esta unidad presentan variaciones de espesor dentro de la Cuenca Catalana. En Alfara y Mont Caro, el espesor de la Fm. Sant Blai varía respectivamente entre unos 23 y $30 \mathrm{~m}$; al tramo superior de la formación corresponden los últimos 4 y $11 \mathrm{~m}$, y los tramos inferior y medio de la formación alcanzan respectivamente 5 ó $6 \mathrm{~m}$ y 14 ó $13 \mathrm{~m}$. La Fm. Sant Blai sobrepasa los $40 \mathrm{~m}$ de espesor en la región de Xerta-Paüls, de los cuales sólo los últimos centímetros corresponden al tramo superior de calizas mudstone, en tanto que el tramo inferior margoso con oolitos ferruginosos está bien representado, alcanzando más de $8 \mathrm{~m}$ de espesor, y el tramo intermedio contiene nódulos de sílex abundantes. En cambio, el tramo superior de esta formación llega a sobrepasar $50 \mathrm{~m}$ de espesor en la región de Tivissa, mientras que el tramo intermedio disminuye de espesor hasta valores inferiores a 8 metros, contiene escasos nódulos de sílex y algunos niveles son de calizas con granos siliciclásticos de hasta 1,5 cm de diámetro; además, el tramo inferior está reducido a 


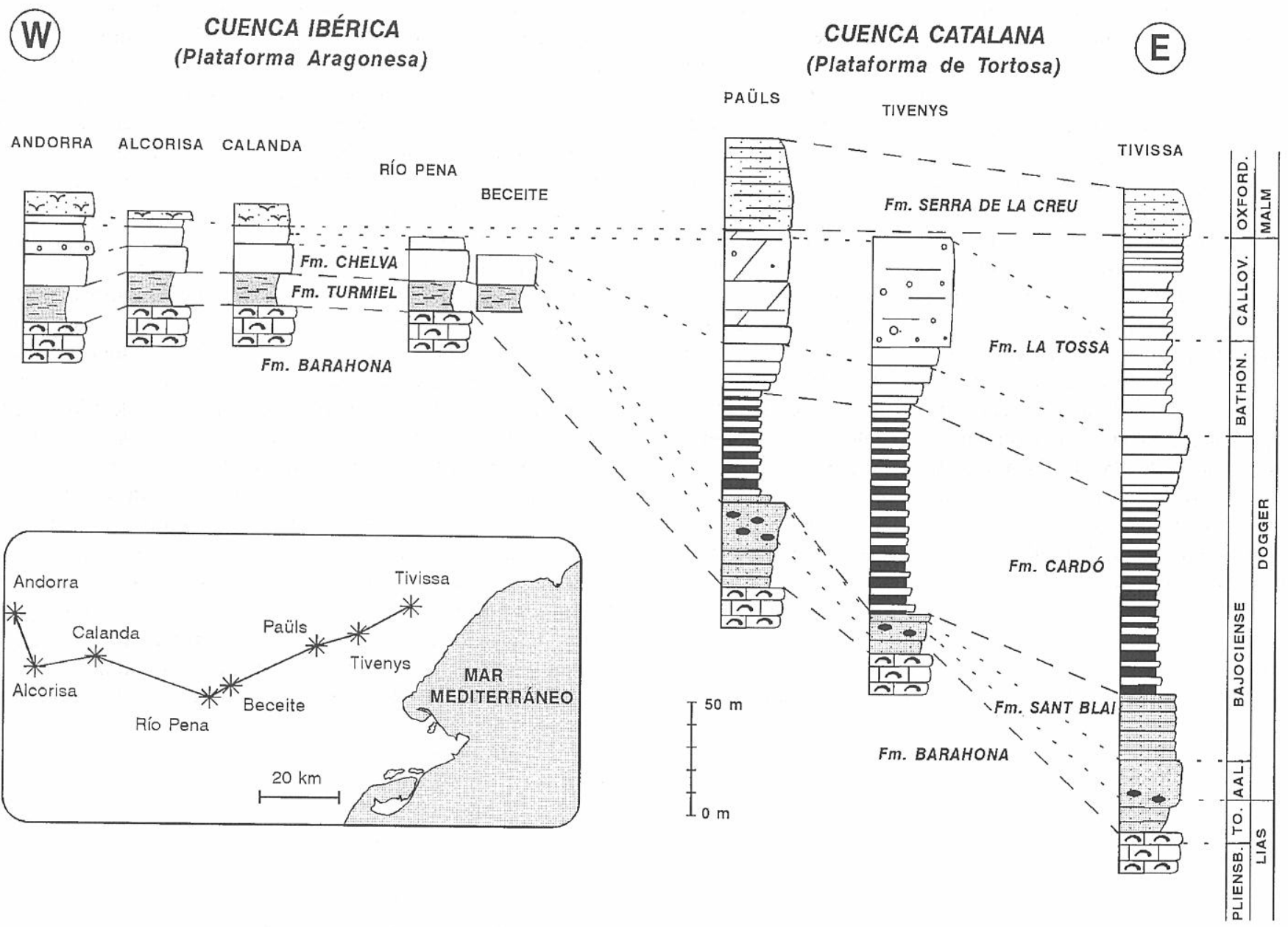

Figura 3. Esquema de correlación litoestratigráfica y cronoestratigráfica entre las columnas representativas del Jurásico Medio en la Plataforma de Tortosa y en la Plataforma Aragonesa. Las unidades litoestratigráficas y las facies situadas por encima de la Fm. Barahona no pueden ser extrapoladas desde una plataforma a la otra. Para las mismas unidades cronoestratigráficas, los espesores del Jurásico Medio son notablemente mayores en la Plataforma de Tortosa que en la Plataforma Aragonesa.

espesores centimétricos e incluso llega a desaparecer. El tramo superior de calizas mudstone con intercalaciones margosas también sobrepasa $46 \mathrm{~m}$ de espesor en las regiones de Llabería y Vandellòs; sin embargo, los tramos inferior y medio están reducidos, su espesor total es menor de $50 \mathrm{~cm}$ (Fig. 4) y algunos niveles contienen elementos reelaborados más antiguos que los niveles infrayacentes (Lám. I). Los tramos inferior y medio de la Fm. Sant Blai también están muy reducidos o ausentes en Cap de Salou, donde los materiales de esta unidad sobrepasan los $14 \mathrm{~m}$ de espesor, corresponden al Bajociense inferior y en la base contienen elementos reelaborados característicos del Toarciense, Aaleniense y Bajociense inferior.

El techo de la Fm. Barahona suele ser más reciente en la Plataforma de Tortosa que en la Plataforma Aragonesa, aunque este límite puede ser diacrónico a escala zonal. Entre Vall Llarga y el Coll de l'Argila (región de Tivenys-Sierra de Cardó), se ha encontrado un ejemplar de Dactylioceras (Orthodactylites) gr. semicelatum (Simpson) en la parte superior de la Fm. Barahona, por lo que dicha formación corresponde no sólo al Pliensbachiense sino también al Toarciense (Biozona Tenuicostatum; Fernández-López y Mouterde, 1985).
Los materiales más recientes de la Fm. Barahona contienen también braquiópodos característicos del Toarciense inferior en el Barranco del Avellanar (al sudeste de Horta de Sant Joan), Mont Caro, Alfara, Xerta-Paüls, Tivenys, Tivissa y Cap de Salou; en particular: Liospiriferina falloti (Corroy) y Quadratirhynchia attenuata (Dubar).

La base de la Fm. Sant Blai es diacrónica a escala de piso. En la localidad tipo, el tramo inferior contiene Hildaites y corresponde al Toarciense inferior (Biozona Serpentinus). Los representantes de Hildoceras lusitanicum Meister e Hildoceras bifrons (Bruguière), característicos de la Biozona Bifrons, son frecuentes en las calizas que contiene oolitos ferruginosos abundantes, del tramo inferior de la Fm. Sant Blai. Este tramo inferior también corresponde al Toarciense inferior y está representado en las regiones de Tivenys-Sierra de Cardó, Xerta-Paüls y Mont Caro-Alfara; en cambio, está muy reducido o ausente en Llabería y Cap de Salou, donde los materiales basales de la formación corresponden al Bajociense inferior (Fig. 7).

El tramo intermedio de la Fm. Sant Blai, de calizas wackestone bioclásticas con delgadas intercalaciones margosas que localmente presentan nódulos de sílex y que a techo con- 
tienen ooides y oolitos ferruginosos o fosfáticos, comprenden materiales del Toarciense superior, del Aaleniense y del Bajociense inferior. En estos materiales son frecuentes los representantes de Pleydellia, Cotteswoldia y Leioceras junto a los de otros grupos taxonómicos más escasos como Tmetoceras y Vacekia, que permiten reconocer las biozonas Aalensis y Opalinum (Toarciense superior y Aaleniense inferior respectivamente). La aparente escasez de Phymatoceratinae y Grammoceratinae en la Cuenca Catalana no es un indicador paleobiogeográfico (cf. Elmi et al. 1989) sino una consecuencia de la escasez de registro estratigráfico, ya que se han encontrado algunos elementos reelaborados cuyos moldes contienen oolitos ferruginosos y forman parte de asociaciones condensadas en las regiones de Xerta-Paüls, Mont Caro y Alfara. El intervalo estratigráfico que comprende las zonas Variabilis, Thouarsense e Insigne es el que presenta mayor grado de condensación estratigráfica del Toarciense (cf. Cadillac et. al., 1981, 1985; Fernández-López y Mouterde, 1985). Los Leioceratinae representan el 88\% de los ammonites del Aaleniense inferior (Biozona Opalinum) y están asociados a Hammatoceratinae $(11 \%)$ y Tmetoceratinae $(1 \%)$. No se ha encontrado registro estratigráfico ni registro fósil de la Biozona Murchisonae (pre-Bradfordensis, Aaleniense). En el resto del Aaleniense (biozonas Bradfordensis y Concavum) también predominan los Graphoceratinae, aunque los
Hammatoceratinae y Tmetoceratinae son más frecuentes que en el Aaleniense inferior. El límite Aaleniense-Bajociense suele estar en el techo del tramo intermedio de la Fm. Sant Blai, donde las calizas wackestone contienen ooides y oolitos ferruginosos asociados a niveles de removilización con litoy bioclastos abundantes, y que presenta asociaciones condensadas con fósiles característicos de las zonas Concavum, Discites y Laeviuscula.

El tramo superior de la Fm. Sant Blai, constituido por calizas mudstone con intercalaciones margosas, corresponde al Bajociense inferior (biozonas Sauzei y Humphriesianum), pero el techo de la unidad es diacrónico a escala zonal. Los materiales del Bajociense inferior tienen espesores centimétricos en las regiones de Xerta-Paüls y Tivenys, en tanto que sobrepasan los $46 \mathrm{~m}$ de potencia en la región de Llabería y los $60 \mathrm{~m}$ en las regiones de Tivissa y Vandellòs. En Cap de Salou, sobre las calizas bioclásticas de la Fm. Barahona de edad Toarciense inferior, hay más de $14 \mathrm{~m}$ de calizas con intercalaciones margosas de la Fm. Sant Blai que pertenecen al Bajociense inferior.

Cadillac et al. $(1981,1985)$ y Canerot et al. (1985) atribuyen a la Fm. Turmiel los materiales considerados en el presente trabajo como el tramo inferior de la Fm. Sant Blai, y a la formación "calcaires de Pauls à chailles" los materiales del tramo intermedio, considerando que sobre ésta última unidad

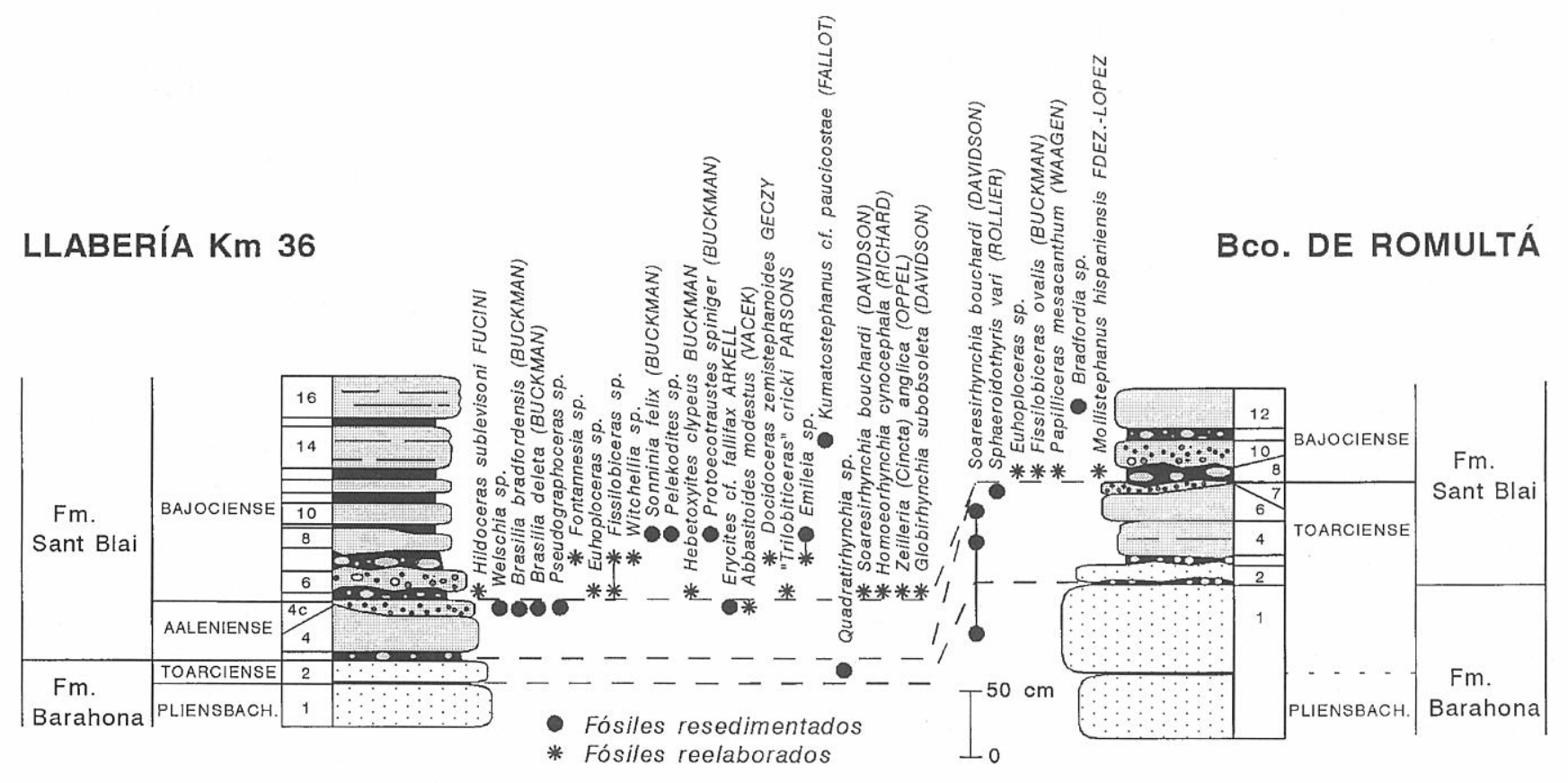

Figura 4. Detalle de los materiales del tránsito Lías/Dogger en la región de Llabería. El desarrollo de los materiales de la Fm. Barahona persistió hasta el Toarciense inferior. En el Barranco de Romultá (4103'13', $0^{\circ} 49^{\prime} 54$ '”), la base de la Fm. Sant Blai son calizas mudstone a wackestone del Toarciense inferior (Bz. Serpentinus; niveles 3-6) cuya superficie superior es irregular y está rellenada por calizas wackestone con oolitos ferruginosos dispersos (nivel 7, Bz. Bifrons). No hay registro estratigráfico del Toarciense superior ni dle Aaleniense. La secuencia toarciense está truncada por una superficie de removilización que está rellenada, a su vez, por calizas del Bajociense inferior con oolitos y ooides ferruginosos (nivel 8), que contienen una asociación condensada con elementos reelaborados característicos de las biozonas Discites y Laeviuscula. En el afloramiento del kilómetro 36 (41'02'49', $0^{\circ} 49^{\prime} 21^{\prime \prime}$ ) hay materiales aaleniense (Biozona Bradfordensis; nivel 4c) y las asociaciones condensadas de la base del Bajociense (niveles 5-7) contienen elementos reelaborados característicos del Toarciense inferior, Aaleniense y Bajociense inferior (pre-Sauzei). En esta región, el intervalo Toarciense inferior (Biozona Serpentinus)-Bajociense inferior (Biozona Laeviuscula) corresponde a secciones condensadas constituidas por sedimentos expandidos que contienen asociaciones condensadas. 
se apoya la Formación Cardó o la formación "calcaires de Beceite à filaments". Sin embargo, estos autores no tienen en cuenta que entre las "calcaires de Pauls à chailles" y las margas de la Formación Cardó se encuentran los materiales del tramo superior de la Fm. Sant Blai, que llegan a sobrepasar $60 \mathrm{~m}$ de espesor. En consecuencia, estas dos unidades propuestas para la Cuenca Catalana, las "calcaires de Pauls à chailles" y las margas de la Fm. Cardó, no son estratigráficamente consecutivas. Por otra parte, los materiales basales de la formación "calcaires de Beceite à filaments" formados en la Plataforma Aragonesa corresponden al Aaleniense inferior y representan el equivalente lateral de las "calcaires de Pauls à chailles" de la Cuenca Catalana; por tanto, estas dos unidades corresponden a dos dominios paleogeográficos diferentes y tampoco son estratigráficamente sucesivas.

\section{Formación Margas de Cardó}

Esta unidad fue definida por Cadillac et al. (1981) y corresponde en parte a la Fm. Tivenys distinguida por Giner (1980; Simó, 1985) y a las margas de Cancellophycus descritas por Bulard (1972). La Fm. Cardó está constituida por calizas margosas y calizas mudstone con intercalaciones de margas, amarillentas en superficie, con texturas y estructuras de bioturbación abundantes, especialmente Zoophycos. Los fósiles son abundantes; en particular, ammonites y Bositra. Aunque otros macrofósiles son escasos, también contienen restos de belemnites, braquiópodos, algunos lamelibranquios bentónicos y equisetales. Los restos de organismos bentónicos sésiles (por ejemplo, crinoideos, espongiarios, briozoarios, serpúlidos o corales) están prácticamente ausentes. Las capas no suelen tener señales de cementaciones tempranas, substratos endurecidos o perforaciones biogénicas. La unidad tiene menor proporción de niveles margosos hacia la parte superior y pasa a ser progresivamente más carbonática. Las superficies de estratificación son netas y las capas tienen gran continuidad lateral; cuando las condiciones de afloramiento permiten realizar observaciones de este tipo, se puede comprobar que la continuidad de las capas suele sobrepasar varios cientos de metros. Los materiales se organizan en secuencias estrato- y granocrecientes de espesores métricos; a excepción de algunas secuencias estrato- y granodecrecientes observadas en la base de la unidad en las regiones de Tivenys, Tivissa y Vandellòs.

El límite inferior de la Fm. Cardó es neto y corresponde en la mayoría de los casos a un substrato endurecido, a un hard-ground, con perforaciones biogénicas y costras ferruginosas, desarrollado sobre los materiales de la Fm. Sant Blai. El límite superior corresponde al cambio litológico entre los materiales fundamentalmente margosos de esta unidad y las calizas o dolomías de la Fm. La Tossa. En la actualidad, los mejores afloramientos se encuentran en la región de Tivenys: en los taludes de dos canteras abandonadas (cerca del km 15,7 y a unos $200 \mathrm{~m}$ al NW del vértice del Coll de Soms, $40^{\circ} 55^{\prime} 53$ ', y $0^{\circ} 30$ '25"'; y en la cantera llamada "Pedrera de Julián", 4056'15' ' y 0²9'49' '; Fernández-López y Mouterde, 1985) así como en el Coll de l'Argila (4056'32', 0³1'10''; Bataller, 1922; Fallot y Blanchet, 1923). Esta formación sobrepasa $100 \mathrm{~m}$ de potencia en la región de TivenysSierra de Cardó. Hacia áreas más septentrionales (Llabería y Cap de Salou) y occidentales (Xerta-Paüls, Mont Caro, Alfa- ra) disminuye su espesor hasta alcanzar valores inferiores a 5 m. Al sur de Horta de Sant Joan (Río de Estrets) el valor de su potencia llega a ser menor de un metro.

La base de la Fm. Cardó es diacrónica a escala zonal. Los materiales basales de esta formación corresponden al Bajociense inferior (biozonas Humphriesianum y Sauzei) en las regiones de Sierra de Cardó, Tivissa, Vandellòs, Llabería y Cap de Salou, en tanto que las primeras capas de la formación pertenecen al Bajociense superior (Biozona Niortense) en las regiones de Tivenys, Xerta-Paüls (Fernández-López, 1983, 1985; Fernández-López y Mouterde, 1985), Mont Caro, Alfara y Horta de Sant Joan. Las subzonas más fosilíferas son la Subzona Baculata (Biozona Niortense) y las subzonas Dichotoma y Subgaranti (Biozona Garantiana). Entre los ammonites predominan los Spiroceratinae, Garantianinae y Leptosphinctinae, que en algunos niveles llegan a estar representados fundamentalmente por individuos jóvenes. Los Lissocerátidos, Oppélidos y Estefanocerátidos, en conjunto, representan menos del 15\%. Los ammonoideos leiostracos (Filoceratáceos y Litoceratáceos) son muy escasos (menos del $0,1 \%$ ) si bien algunos ejemplares corresponden a individuos jóvenes (Fernández-López, 1983; Fernández-López y Mouterde, 1985; Fernández-López y Meléndez, 1995a).

\section{Formación Calizas y dolomías de La Tossa}

El corte tipo de esta formación está en el término municipal de Tivissa, en la ladera septentrional de la Serra de la Creu, unos $2 \mathrm{~km}$ al SE de la población de Tivissa, y a unos $800 \mathrm{~m}$ en dirección ESE del vértice denominado Latosa en la Hoja del MTN 32-18 (471), siendo sus coordenadas geográficas: $41^{\circ} 01^{\prime} 40^{\prime \prime}$ y $0^{\circ} 44^{\prime} 49^{\prime}$ '. La referencia nominal a éste vértice, en vez de a la población de Tivissa, evita las posibles confusiones y homonimias entre esta formación y la Fm. Calizas y/o dolomías y margas con ammonites de Tivissa que ha sido utilizada por otros autores para materiales del Muschelkalk superior de la Cuenca Catalana (cf. Mateu Ibars y Marzo, 1985; Calvet et al., 1987, 1990).

El límite inferior de la Fm. La Tossa es transicional con la Fm. Cardó. El límite superior es neto y coincide con una discontinuidad de extensión regional entre el Jurásico Medio y el Jurásico Superior. La Fm. La Tossa puede ser subdividida en tres tramos en la localidad tipo. El tramo inferior está constituido por calizas mudstone a wackestone de microfilamentos, con delgadas intercalaciones margosas. El tramo intermedio corresponde a calizas mudstone y calizas margosas, con superficies de estratificación netas. El tramo superior son calizas mudstone a wackestone de bioclastos, con frecuentes niveles de removilización así como hard-grounds y costras ferruginosas locales. En los tres tramos, los materiales se organizan en secuencias estrato- y granocrecientes, de espesores métricos; a excepción de algunas secuencias estrato- y granodecrecientes desarrolladas en el tramo intermedio. Los fósiles son frecuentes; en particular, ammonites y Bositra. Las estructuras de bioturbación son abundantes (Zoophycos y Thalassinoides).

De los tres tramos distinguidos en el área tipo de la Fm. La Tossa, el tramo inferior es el de mayor continuidad lateral (35 m en Tivissa, $30 \mathrm{~m}$ en Tivenys, Mont Caro, Alfara y Xerta-Paüls, $5 \mathrm{~m}$ en Llabería). En cambio, los tramos intermedio y superior muestran notables variaciones laterales 


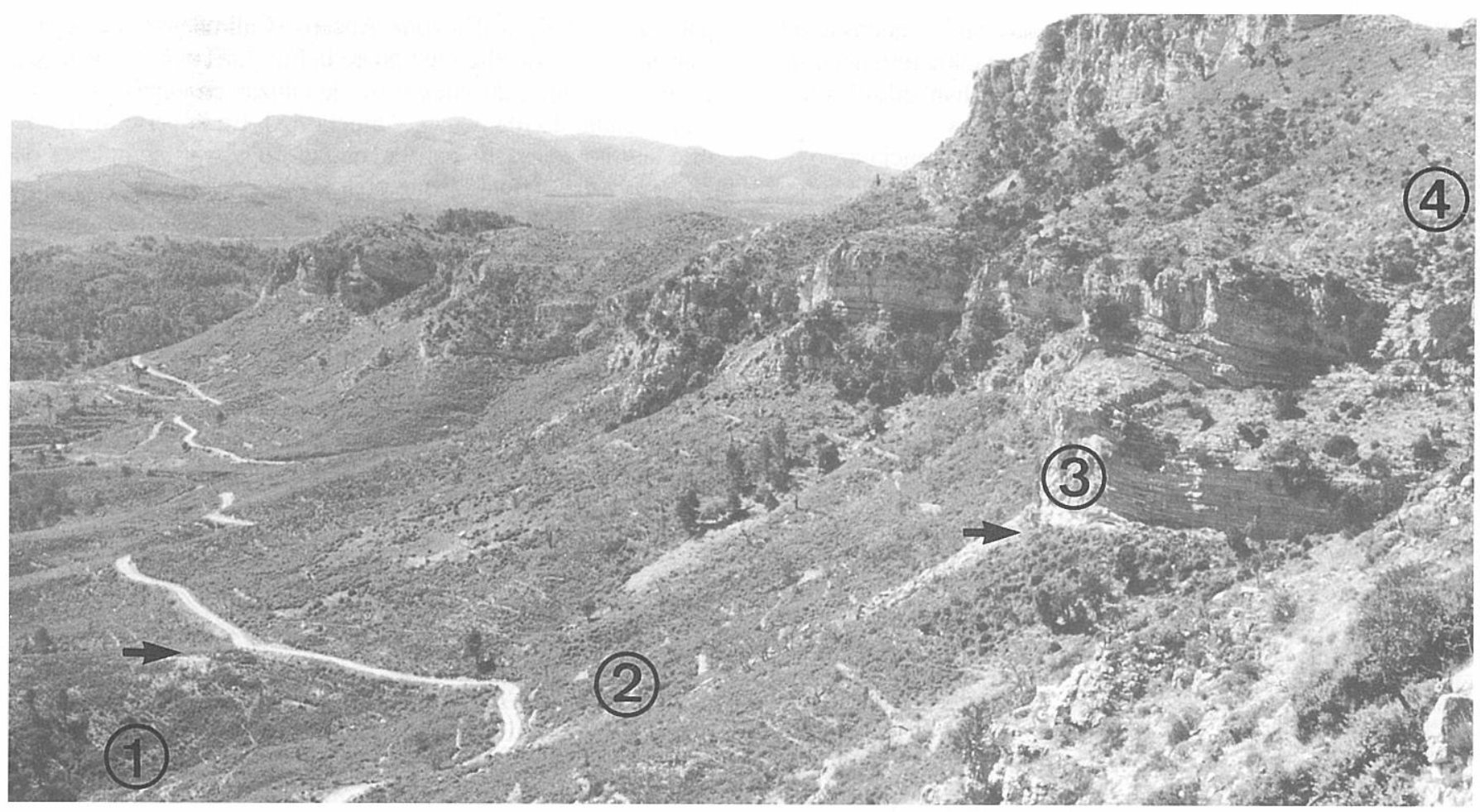

Figura 5. Materiales del Jurásico Medio en la Serra de la Creu (Tivissa). Sobre la Fm. Calizas y calizas margosas de Sant Blai (1) se encuentra la Fm. Margas de Cardó (2). A continuación, las calizas mudstone a wackestone de microfilamentos (3) y las calizas mudstone y calizas margosas (4) que respectivamente constituyen el tramo inferior e intermedio de la Fm. La Tossa en la localidad tipo. Las flechas indican los límites de las formaciones.

tanto de espesor como de facies (Figs. 5 y 6). Las calizas mudstone a wackestone en capas delgadas que constituyen los tramos intermedio y superior, con más de $90 \mathrm{~m}$ de espesor total en Tivissa, pasan lateralmente a packstone y grainstone oolíticos en bancos gruesos con geometría de barras, en la región de Sierra de Cardó-Tivenys. En la región de XertaPaüls, donde alcanzan los $90 \mathrm{~m}$ de potencia y con valores menores al sur de Horta de Sant Joan, corresponden a facies generalmente dolomíticas, dispuestas en bancos gruesos, que han sido atribuidas por Simó (1985) a la Fm. Campanillas distinguida por Giner (1980).

La Fm. La Tossa comprende materiales del Bajociense Superior, del Bathoniense y del Calloviense. El límite transicional entre la Fm. Cardó y la Fm. La Tossa es diacrónico a escala zonal, aunque en menor grado que la base de la Fm. Cardó (Fig. 7). Las primeras calizas con microfilamentos de la Fm. La Tossa contienen Bajocisphinctes bajociensis (Siemiradzki), Garantiana gr. garantiana (d'Orbigny) y otros ammonites de la parte inferior y media de la Biozona Garantiana en las regiones de Xerta-Paüls, Alfara y Mont Caro; en cambio, contienen respectivamente ammonites de la parte superior de la Biozona Garantiana (Hlawiceras spp.) y de la Biozona Parkinsoni (Parkinsonia spp.) en las regiones de Tivenys-Sierra de Cardó, Tivissa y Vandellòs.

Los materiales bathonienses alcanzan una potencia de unos $40 \mathrm{~m}$ en las regiones de Tivissa y Vandellòs. Entre los ammonites bathonienses predominan los Perisfínctidos y los Oppélidos. El Bathoniense superior, rara vez registrado en la Cuenca Ibérica, está representado en las regiones de Tivissa y Vandellòs por materiales carbonáticos sin condensación

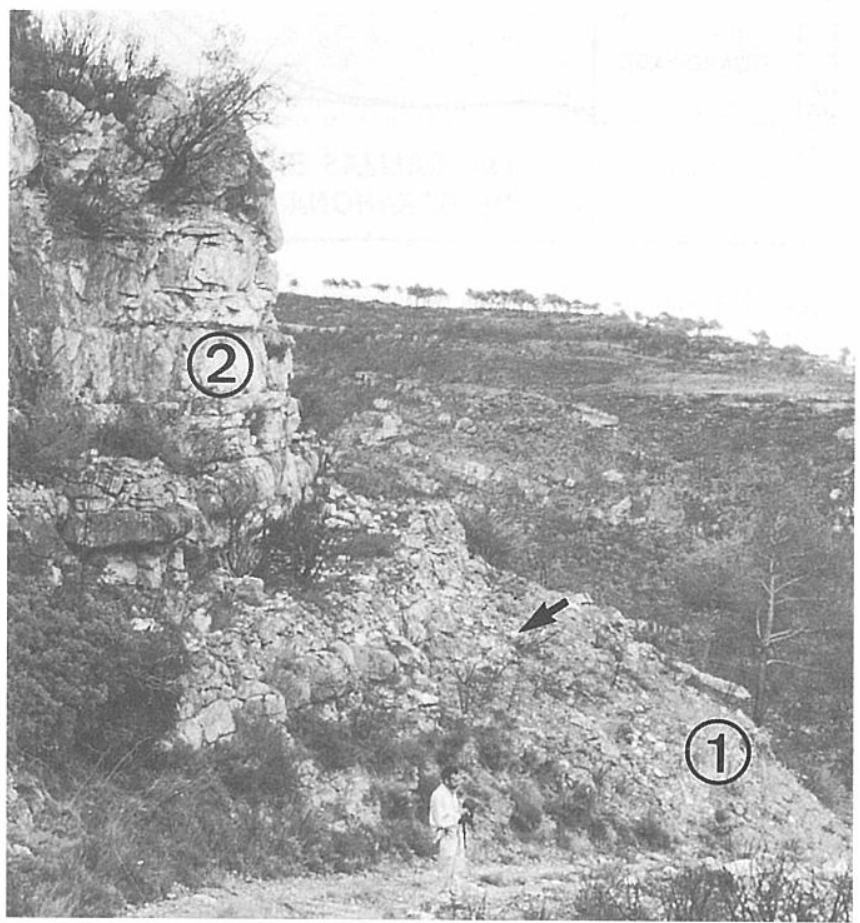

Figura 6. Límite entre la Fm. Margas de Cardó (1) y la Fm. Calizas y dolomías de La Tossa (2), en la vertiente derecha del Barranco de Romultá (Llabería). La flecha indica el límite entre las dos formaciones. 
sedimentaria, y asociaciones registradas sin condensación tafonómica, que contienen Epistrenoceras característicos de la Biozona Retrocostatum. Sin embargo, no han sido reconocidos todavía materiales de la Biozona Discus.

Los materiales callovienses tienen una potencia aproximada de $45 \mathrm{~m}$ en la Serra de la Creu y forman la mitad superior de la Fm. La Tossa. En la parte inferior ( $25 \mathrm{~m}$ ) los materiales corresponden a tramo intermedio distinguido en esta formación: calizas mudstone y calizas margosas, de color gris claro, con superficies de estratificación netas. Este tramo contiene frecuentes Macrocephalites, así como representantes de las subfamilias Hecticoceratinae (Hecticoceras) y Pseudoperisphinctinae (Homoeoplanulites). Este intervalo corresponde a la biozona inferior del Calloviense (Biozona Herveyi).

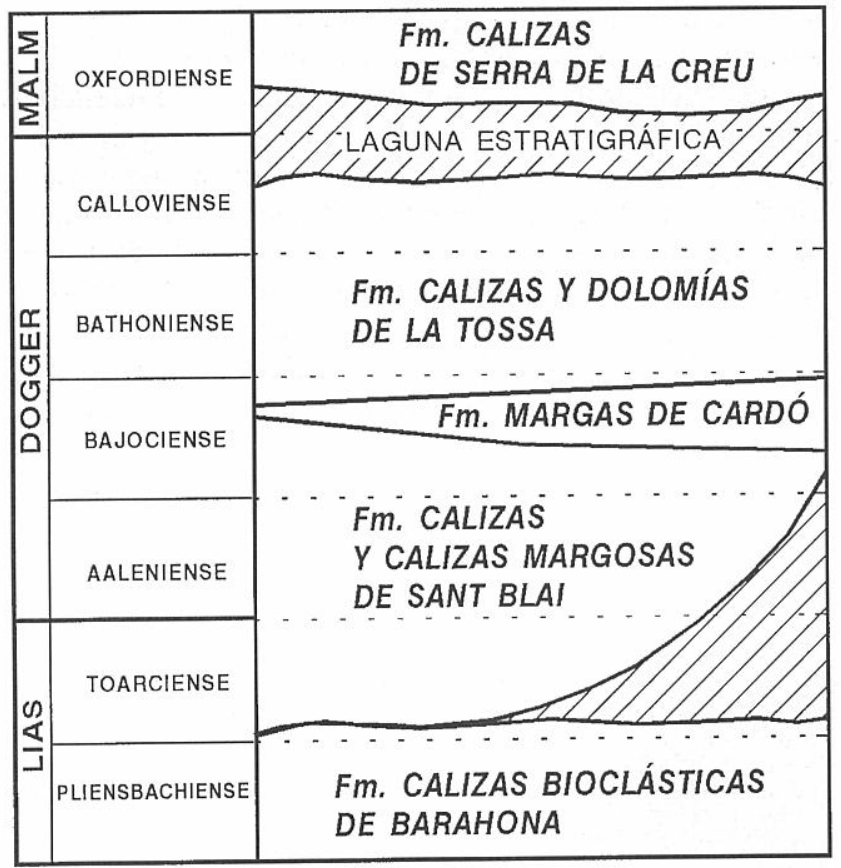

Figura 7. Esquema de las relaciones cronoestratigráficas entre los materiales de las distintas unidades litoestratigráficas en la Cuenca Catalana.

El tramo superior de la Fm. La Tossa en la localidad tipo alcanza unos $20 \mathrm{~m}$ de espesor y está constituido por una sucesión regular de calizas bioturbadas, wackestone, de color grispardo, estratificadas en capas regulares, con filamentos y bioclastos, que contienen frecuentes ammonites. En la parte inferior, de 4,5 $\mathrm{m}$ de potencia, se ha recogido frecuentes ejemplares de Macrocephalites, Homoeoplanulites y, hacia la parte superior, R. (Rehmania). En un segundo tramo, de calizas compactas (mudstone a wackestone de filamentos) se han encontrado escasos perisfínctidos (Homoeoplanulites) y Hecticoceras. Estos dos primeros tramos representan aún las biozonas Macrocephalus y Gracilis, del Calloviense inferior. Sigue un tramo de $6,5 \mathrm{~m}$ de espesor formado por calizas margosas y margocalizas que pasan a calizas más compactas hacia el techo. En la parte inferior se han recogido varios ejemplares de Hecticoceras (Chanasia) de talla grande, que caracterizan probablemente la

parte inferior de la Biozona Anceps (Calloviense medio; cf. Cariou, 1987). En el corte tipo de la Fm. La Tossa se distingue un último tramo, de unos $6 \mathrm{~m}$, de calizas en capas regulares (wackestone de filamentos y bioclastos). En la parte media de éste último tramo se han encontrado algunos ejemplares de Hecticoceras (Brightia) que podrían caracterizar la parte inferior de la Biozona Coronatum (Biohorizonte Villanyensis, Calloviense medio). Los materiales del Jurásico Medio terminan en una superficie de removilización con ammonites reelaborados (Hecticoceratinae, Grossouvriinae) que localmente presenta pátinas o delgadas costras ferruginosas (Fig. 8).

Los afloramientos de la Fm. La Tossa más septentrionales se encuentran en la región de Llabería (Fig. 6), aunque han sido erróneamente datados y consecuentemente se ha propuesto la existencia de "klippes" y "ventanas tectónicas" en esta región (cf. Núñez et al., 1980; Maldonado et al., 1986; Losantos et al. 1989).

\section{Formación Calizas de Serra de la Creu}

Esta unidad equivale al Miembro Serra de la Creu definido por Salas (1987) que ha sido utilizado en los trabajos de Salas (1989) y Aurell et al. (1990). El corte tipo se encuentra al SE de Tivissa, en la Serra de la Creu, en continuidad topográfica con el corte tipo de la Fm. La Tossa. Sus coordenadas

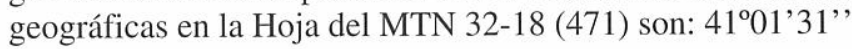
y $0^{\circ} 44^{\prime} 41^{\prime \prime}$.

Los materiales de la Fm. Serra de la Creu son calizas tableadas, en capas de 20 a $40 \mathrm{~cm}$, cuyo espesor total varía entre los $25 \mathrm{~m}$ en la Serra de la Creu y los $40 \mathrm{~m}$ en la región de Xerta-Paüls. En la Serra de la Creu, hacia la base de la unidad, predomina la facies de packstone de peloides y ooides, mientras que a techo dominan los packstones de peloides. Los ooides no superan $1 \mathrm{~mm}$ de diámetro, presentan núcleos bioclásticos y una corteza formada por láminas micríticas. Los peloides y ooides pueden estar agregados. En estas facies se encuentran, dispersos, restos de equinodermos, ammonites, belemnites, protoglobigerinas, bivalvos, gasterópodos y esponjas, bien como espículas o como tuberoides. Además se encuentran oncoides, que consisten en intraclastos y bioclastos envueltos por láminas muy irregulares de algas y colonizados por serpúlidos. En la región de Xerta-Paüls, dominan

XERTA - PAÜLS
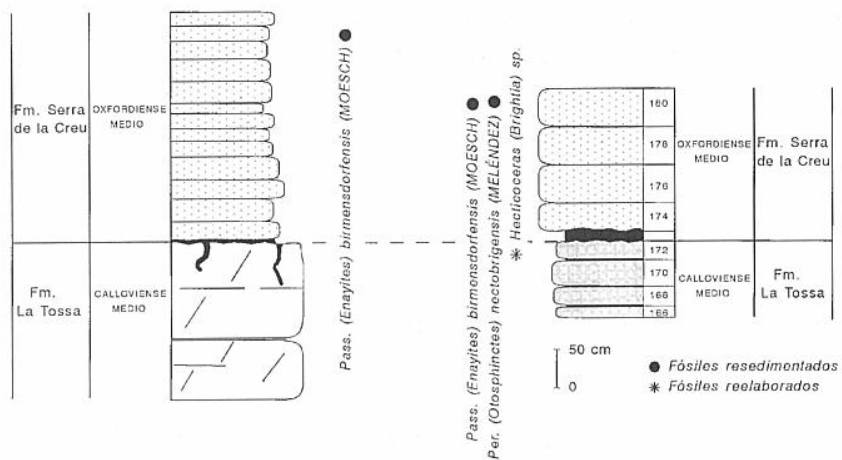

Figura 8. Detalle de los materiales del tránsito Dogger/Malm en las regiones de Serra de la Creu y Xerta-Paüls. 
las facies de packstone a wackestone bioclásticos, bioturbados, con abundantes restos de esponjas, generalmente como espículas o fragmentos de pequeño tamaño, si bien se pueden encontrar algunos ejemplares enteros o escasamente fragmentados. Además son abundantes los restos de equínidos, bivalvos y protoglobigerinas. Los peloides y ooides están dispersos o bien forman niveles intercalados, de algunos decímetros, donde son los componentes dominantes.

El límite inferior de la Fm. Serra de la Creu es neto y corresponde a la discontinuidad de extensión regional entre el Jurásico Medio y el Jurásico Superior, situada al techo de la Fm. La Tossa. Por encima de la Fm. Serra de la Creu se encuentran las calizas micríticas tableadas de la Fm. Polpís (Salas, 1987).

En el corte tipo (Fig. 8), sobre la superficie con pátinas y costras ferruginosas locales del techo de la Fm. La Tossa, hay un nivel de removilización con fósiles reelaborados y asociaciones condensadas, que ponen de manifiesto una laguna estratigráfica desde el Calloviense medio hasta el Oxfordiense medio. En los primeros metros de esta unidad se han recogido varios ejemplares de Perisphinctes (Otosphinctes) nectobrigensis Meléndez, Per. (Dichotomosphinctes) luciaeformis Enay y Passendorferia (Enayites) cf. birmensdorfensis (Moesch). A unos $10 \mathrm{~m}$ de la base se ha encontrado Larcheria cf. iberica Fontana. A continuación, por encima de unos niveles con escasos ejemplares de Per. (Dichotomosphinctes) wartae Bukowski, hay unos bancos más compactos con ejemplares muy abundantes de Perisphinctes (Dichotomoceras) de los grupos bifurcatoides Enay - duongi Meléndez. Estos bancos marcan el límite entre las biozonas Transversarium y Bifurcatus (Oxfordiense medio; cf. Cariou y Meléndez, 1990). Después, los materiales están bastante cubiertos. Los últimos niveles son de calizas en capas irregulares y con superficies ferruginosas, que contienen Orthosphinctes (Planisphinctes) aff. freybergi Geyer y Subnebrodites próximos al grupo S. planula (Quenstedt), característicos de la parte inferior de la Biozona Planula (Oxfordiense superior).

La sucesión bioestratigráfica de ammonoideos en el corte de Xerta-Paüls es muy similar a la de la Serra de la Creu, aunque presenta mayor espesor. En los primeros $6 \mathrm{~m}$ se han recogido varios ejemplares de Otosphinctes y $\mathrm{Pa}$ ssendorferia característicos de la Biozona Transversarium, Subbiozona Luciaeformis (Oxfordiense medio). A 12,5 m de la base se ha recogido Perisphinctes jelskii Siemiradzki junto a otras formas que caracterizan la base de la Subbiozona Rotoides (Oxfordiense medio), y un poco más arriba Per. (Dichotomosphinctes) gr. wartae Bukowski. El límite entre las biozonas Transversarium y Bifurcatus se encuentra aproximadamente a $14 \mathrm{~m}$ de la base, en un banco similar al de la Serra de la Creu, con abundantes ejemplares de Perisphinctes (Dichotomoceras) de los grupos bifurcatoides Enay - stenocycloides Siemiradzki. Por encima, la sucesión es menos fosilífera; sin embargo, los últimos niveles contienen diversas formas de Subnebrodites y Orthosphinctes, características de la Subbiozona Planula del Oxfordiense superior.

\section{ELEMENTOS PALEOGEOGRÁFICOS}

En la reconstrucción paleogeográfica de la zona de entronque (Zona de Enlace, en Guimerà 1983, 1984; Gonzá- lez y Guimerà, 1993) entre la Cordillera Costero-Catalana y la Cordillera Ibérica, durante el Jurásico Medio, cabe distinguir los siguientes elementos: la Cuenca Catalana, la Cuenca Ibérica, el Macizo Catalán y el Alto de El Maestrazgo (Fig. 12). Desde el punto de vista paleogeográfico también son relevantes las semejanzas y diferencias encontradas entre las unidades litoestratigráficas del Jurásico Medio de la Cuenca Catalana y las de Mallorca.

\section{Cuenca Catalana}

Durante el Jurásico Medio, en la Cuenca Catalana puede distinguirse una plataforma subsidente, la Plataforma de Tortosa (Figs. 9 y 12), en la que se desarrollaron secciones expandidas, con más de $350 \mathrm{~m}$ de potencia y espesores considerablemente superiores a los de las áreas colindantes (Fernández-López et al., 1994). Estas secciones están constituidas por facies de plataforma abierta, con algunas secuencias de profundización desarrolladas durante el Bajociense.

La Plataforma de Tortosa comenzó a diferenciarse durante el Toarciense inferior. Durante el resto del Toarciense, el Aaleniense y el Calloviense medio-Oxfordiense inferior sólo se desarrollaron secciones condensadas en facies de plataforma abierta (Fig. 10). La ausencia virtual de registro estratigráfico y de registro fósil de la Biozona Murchisonae (Aaleniense), de la Biozona Discus (Bathoniense), así como del Calloviense superior y del Oxfordiense inferior sugiere que el desarrollo de estas discontinuidades regionales presentes también en la Cuenca Ibérica se debió a factores externos que afectaron a ambas cuencas. Los valores máximos de subsidencia y de tasa de sedimentación se alcanzaron durante el Biocrón Garantiana (Bajociense superior) dando lugar a secciones expandidas que sobrepasan $60 \mathrm{~m}$ de espesor.

Tanto los restos de ammonites como los de diversos organismos bentónicos (braquiópodos, lamelibranquios, crinoideos y gasterópodos) son frecuentes en los materiales del Jurásico Medio desarrollados en la Plataforma de Tortosa. Las asociaciones registradas de ammonites están constituidas por poblaciones tafónicas de tipo-3 o de tipo-2 (FernándezLópez, 1983, 1985, 1995; Fernández-López y Mouterde, 1985) con elementos resedimentados o reelaborados. En estas poblaciones, los representantes de cada género muestran predominio de conchas adultas, tienen distribuciones de frecuencias de tamaño normales o con sesgo negativo, los individuos juveniles son muy escasos o están ausentes, la proporción entre el número de elementos conservados y el número de especies representadas tiene valores muy bajos, y puede estar representado sólo uno de los dimorfos (las macroconchas o las microconchas). En los materiales de las biozonas Niortense y Garantiana se encuentran algunas poblaciones tafónicas de ammonites de tipo-1, con elementos acumulados y valores nulos de condensación tafonómica, donde las proporciones de restos de organismos bentónicos son mínimas. En estas poblaciones tafónicas de tipo-1 predominan los individuos jóvenes, las distribuciones de frecuencias de tamaño para los representantes de cada género son unimodales y asimétricas con sesgo positivo, suelen ser monoespecíficas y están representadas macroconchas y microconchas.

Los datos estratigráficos y sedimentológicos junto a los tafonómicos y paleoecológicos indican que los valores paleo- 


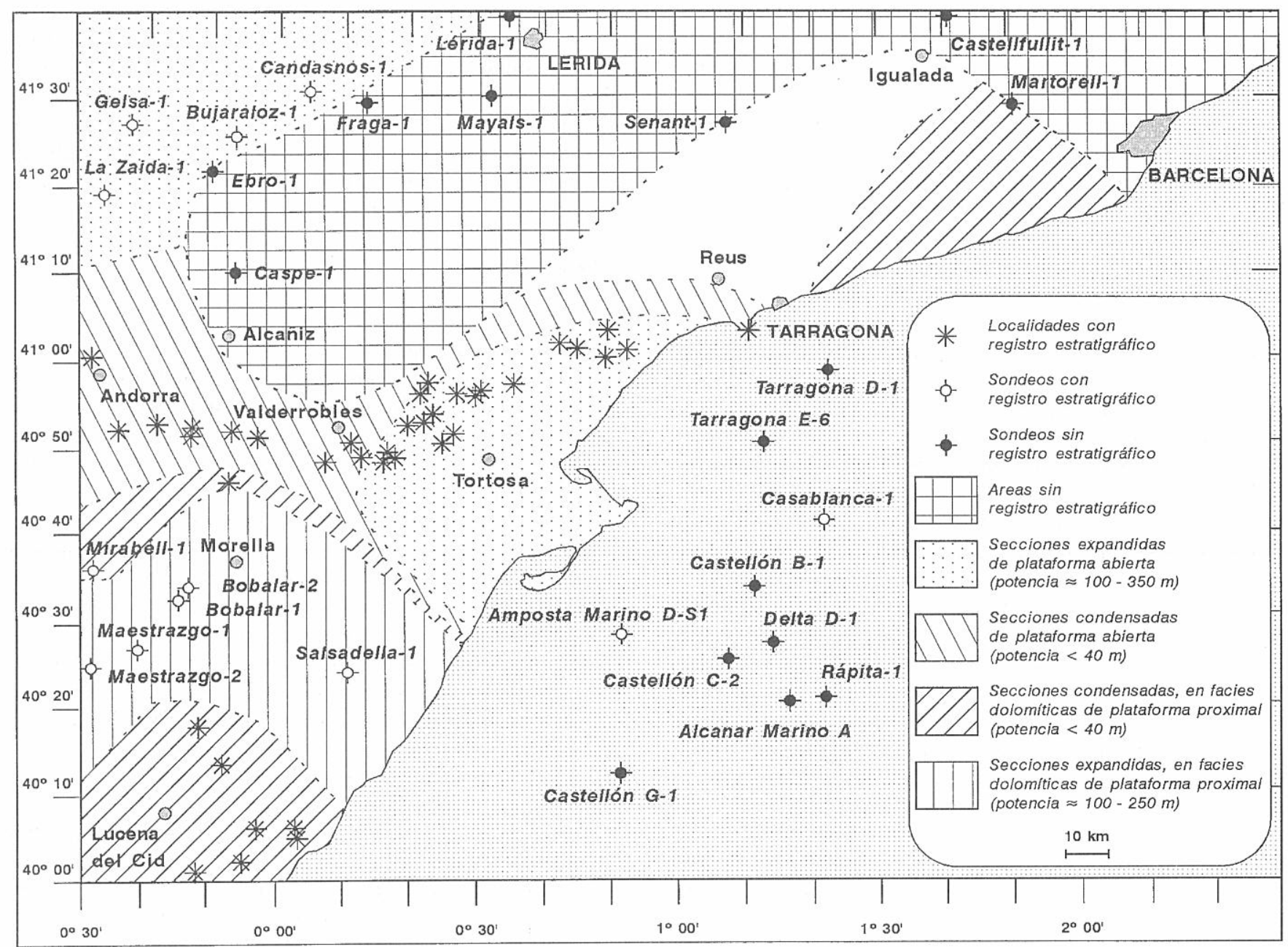

Figura 9. Mapa de contornos de isotasas de los materiales del Jurásico Medio en la Cuenca Catalana, Alto de El Maestrazgo y sector oriental de la Plataforma Aragonesa.

batimétricos máximos en esta cuenca se alcanzaron durante los biocronos Niortense y Garantiana, cuando la cuenca llegó a ser colonizada por algunas poblaciones de ammonites (Fernández López y Mouterde, 1985; Fernández-López, 1995; Fernández López y Meléndez, 1995a). Por el contrario, los valores paleobatimétricos mínimos corresponden a intervalos del Toarciense (biocronos Variabilis, Thouarsense e Insigne), Aaleniense-Bajociense inferior (biocronos Murchisonae, Concavum, Discites y Laeviuscula), Bathoniense superior (Biocrón Discus) y del tránsito Calloviense medio-Oxfordiense inferior (biocronos Atleta, Lamberti, Mariae y Cordatum). Durante estos episodios con valores paleobatimétricos mínimos se desarrollaron secciones condensadas constituidas por sedimentos expandidos, que contienen asociaciones de tipo-3 con altos valores de condensación tafonómica y elementos reelaborados que muestran facetas elipsoidales de desgaste (Fernández López y Gómez, 1991; Gómez y Fernández López 1992, 1995; Fernández López y Meléndez 1994, 1995b).

En las asociaciones registradas de ammonites de la Cuenca Catalana predominan los taxones característicos de los mares epicontinentales del NW de Europa. Los ammonoideos filoceratáceos y litoceratáceos, característicos del
Tethys y que habitaron preferentemente en ambientes pelágicos y oceánicos, son muy escasos; incluso en la Biozona Garantiana, donde han sido encontradas varias conchas de filoceratáceos jóvenes, sólo representan proporciones inferiores al $0,1 \%$. No obstante, durante el Biocrón Garantiana ocurrieron procesos de colonización por elementos característicos de áreas mediterráneas (en particular, Bajocisphinctes-Microbajocisphinctes y Trimarginia, Fernández-López, 1983, 1985). Entre los organismos bentónicos más significativos, tales como los braquiópodos, también predominan taxones característicos de los ámbitos paleobiogeográficos del NW de Europa (Loboidothyris, Sphaeroidothyris, Rhynchonelloidella, Tubithyris); si bien, durante el Toarciense y hasta el Aaleniense inferior, se encuentran especies que corresponden a la "fauna española" de Choffat (1880; cf. Dubar, 1931; García Joral y Goy, 1984, 1994).

La sucesión estratigráfica descrita en los apartados anteriores, con más de $350 \mathrm{~m}$ de espesor total, es característica de la Plataforma de Tortosa y puede ser identificada en los sondeos Amposta Marino D-S1 y Casablanca-1 (cf. Lanaja, 1987; Maldonado et al. 1986), lo cual confirma la prolongación de esta plataforma más allá de los límites de la línea de costa actual (Fig. 9). Al nordeste de la Plataforma de Tortosa 


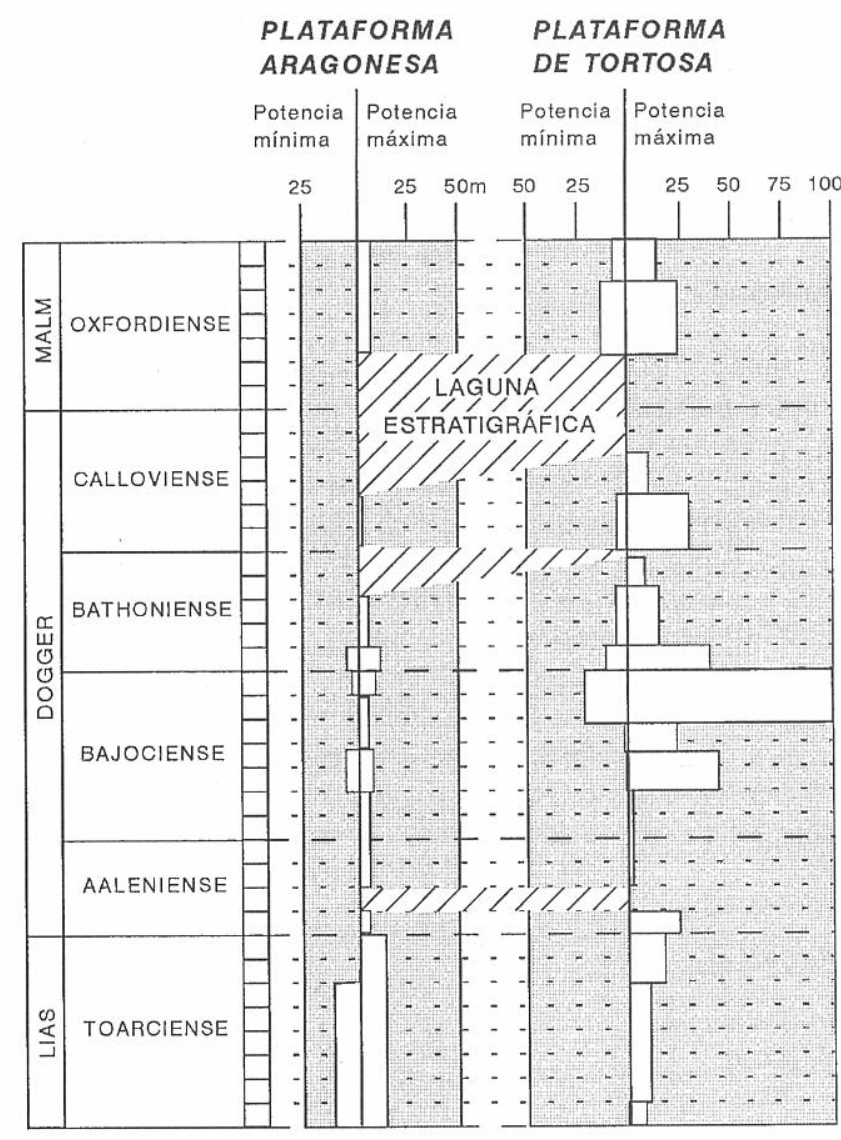

Figura 10. Esquema de las variaciones de potencia a escala zonal del Jurásico Medio en la Plataforma Aragonesa y en la Plataforma de Tortosa. Las lagunas estratigráficas comunes corresponden al Aaleniense (Biozona Murchisonae), al Bathoniense (Biozona Discus) y al tránsito Calloviense-Oxfordiense (biozonas Atleta, Lamberti, Mariae y Cordatum). En la Plataforma de Tortosa destaca el notable espesor que alcanzan los materiales del Bajociense superior (biozonas Niortense y Garantiana); en cambio, los materiales toarcienses y aalenienses llegan a estar ausentes.

se encuentra una región caracterizada por el desarrollo de facies dolomíticas de plataforma proximal, en la que son menores los espesores del Jurásico Medio e incluso pueden faltar los materiales de esta edad (cf. Calzada y Vía, 1971; Esteban y Julià, 1973; Robles Orozco, 1974, 1975; Esteban y Robles, 1979; Anadón et al. 1982; Barale y Calzada, 1985), que corresponde a una zona de umbral denominada Alto de Tarragona (Salas y Casas, 1993). Un cinturón de facies de plataforma proximal, a veces con un sistema de barras oolíticas y dolomías, se desarrolló al menos durante el Bathoniense entre la plataforma subsidente y la zona de alto con facies dolomíticas. Estas facies de plataforma proximal llegaron a progradar localmente sobre los materiales de la plataforma abierta subsidente.

\section{Cuenca Ibérica}

Al oeste de la Cuenca Catalana se encuentra la porción más oriental de la Cuenca Ibérica (cf. Gautier y Mouterde,
1964; Rosell Sanuy y Vía Boada, 1967; Bulard, 1972; Marín et al., 1977; Lanaja, 1987; Fontana et al., 1995). El Jurásico Medio está representado en esta región por secciones expandidas de plataforma abierta $(80-100 \mathrm{~m}) \mathrm{y}$, lateralmente hacia el sudeste, por secciones condensadas (20-25 m) de la Plataforma Aragonesa (Figs. 9 y 12). Aunque tienen escaso espesor, estas secciones condensadas pueden ser incluidas en la Fm. Chelva y presentan claras diferencias faciales con los materiales que rellenan la Plataforma de Tortosa (Fig. 3). Las calizas con microfilamentos que afloran en la región de Beceite están en contacto mecánico con los materiales margosos de la Fm. Turmiel, sólo suelen representar parte del Aaleniense y del Bajociense debido a los procesos de erosión ocurridos durante el Cretácico, y no pueden ser utilizadas como referente litoestratigráfico de los materiales del Jurásico Medio de la Plataforma Aragonesa.

Los restos de ammonites y de diversos organismos bentónicos (tales como braquiópodos, lamelibranquios, crinoideos, espongiarios, serpúlidos y gasterópodos) son abundantes en los sedimentos de la Plataforma Aragonesa. Las asociaciones registradas de ammonites son de tipo-3, sin elementos acumulados y con una alta proporción de elementos reelaborados. Los valores máximos de condensación tafonómica y de condensación estratigráfica se alcanzaron durante los biocronos Murchisonae-Laeviuscula (Aaleniense-Bajociense inferior), Niortense-Garantiana (Bajociense superior), Subcontractus-Discus (Bathoniense) y durante el tránsito Calloviense/Oxfordiense (Fig. 10).

La Cuenca Catalana estuvo comunicada con la Cuenca Ibérica a través de una zona de estrecho de la Plataforma Aragonesa, que corresponde en parte con la actual región de los puertos de Beceite y que hemos denominado Estrecho de Beceite (Fig. 12; Fernández-López et al., 1994).

\section{Macizo Catalán}

La información del subsuelo proporcionada por los sondeos Caspe-1, Ebro-1, Fraga-1, Mayals-1, Senant-1, Lérida1, Castellfullit-1 y Martorell-1, pone de manifiesto la ausencia de materiales del Jurásico Medio en una amplia región (cf. Stoeckinger, 1976; Lanaja, 1987) como consecuencia de procesos de erosión y no-sedimentación. Esta región sin registro estratigráfico se distribuye con una orientación nordeste-sudoeste y estuvo ocupada al menos en parte por un macizo emergido denominado Macizo Catalán (Canerot et al., 1984; Wilde, 1988). Es difícil precisar el límite sudoeste del Macizo Catalán durante el Jurásico Medio, debido a la mencionada erosión post-jurásica. No obstante, teniendo en cuenta las pautas de distribución de las facies en la Plataforma Aragonesa y en la Plataforma de Tortosa, el límite trazado en las figuras 9 y 12 representa una extensión superior a la de este elemento paleogeográfico, cuya actuación estuvo controlada al menos en parte por un importante accidente tectónico meridional de dirección SW-NE.

\section{Alto de El Maestrazgo}

La influencia de este elemento paleogeográfico ha sido reconocida previamente por varios autores (cf. Canerot, 1974, 1991; Burollet y Winnock, 1977; Cadillac et al., 1981; Canerot et al., 1984, 1985) aunque su actuación no fue uni- 


\begin{tabular}{|c|c|c|c|c|}
\hline \multicolumn{2}{|r|}{$\begin{array}{l}\text { CUENCA IBÉRICA } \\
\text { (Goy et al., 1976; } \\
\text { Gómez y Goy, 1979) }\end{array}$} & \multirow{2}{*}{$\begin{array}{c}\text { CUENCA CATALANA } \\
\text { (Unidades definidas on este trabajo) } \\
\text { Fm. Calizas } \\
\text { de Serra de la Creu } \\
\text { (Salas, 1987, 1989) } \\
\end{array}$} & \multicolumn{2}{|c|}{$\begin{array}{l}\text { MALLORCA } \\
\text { (Alvaro ot al. 1989) }\end{array}$} \\
\hline \multirow{4}{*}{ 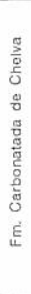 } & $\begin{array}{l}\text { Mb. Calizas con esponjins } \\
\text { de Yastova }\end{array}$ & & $\begin{array}{l}\text { Fm. Calizas } \\
\text { nodulosas } \\
\text { de Allábia }\end{array}$ & $\begin{array}{l}\text { Fm. Margas } \\
\text { radiodariticas } \\
\text { del Puig de } \\
\text { Ses Fites }\end{array}$ \\
\hline & $\begin{array}{l}\text { Capa de Oolitos terru- } \\
\text { ginosos de Artroyotrio }\end{array}$ & $\begin{array}{l}\text { Fm. Calizas y dolomías } \\
\text { de La Tossa }\end{array}$ & \multicolumn{2}{|c|}{$\begin{array}{l}\text { Fm. Calizas } \\
\text { del Puig d'en Paró }\end{array}$} \\
\hline & "parto media" & $\begin{array}{l}\text { Fm. Margas de Cardó } \\
\text { (Cadillac et al. 1981) }\end{array}$ & \multicolumn{2}{|c|}{$\begin{array}{l}\text { Fin. Calizas y margocalizas } \\
\text { do Cúber }\end{array}$} \\
\hline & $\begin{array}{l}\text { Mb. Calizas nodulosas } \\
\text { de Casinos }\end{array}$ & \multirow{2}{*}{$\begin{array}{l}\text { Fm. Calizas y calizas margosas } \\
\text { de Sant Blai }\end{array}$} & \multirow{2}{*}{\multicolumn{2}{|c|}{$\begin{array}{l}\text { Fm Margocalizas y calizas } \\
\text { nodulosas de Gorg Blau }\end{array}$}} \\
\hline & $\begin{array}{l}\text { n. Alternancia de margas } \\
\text { calizas de Turmiel }\end{array}$ & & & \\
\hline \multicolumn{2}{|c|}{$\begin{array}{l}\text { Fm. Calizas bioclásticas } \\
\text { de Barahona }\end{array}$} & $\begin{array}{l}\text { Fm. Calizas bioclásticas } \\
\text { de Barahona }\end{array}$ & \multicolumn{2}{|c|}{$\begin{array}{l}\text { Fm. Calizas encriniticas } \\
\text { de Es Cosconar }\end{array}$} \\
\hline
\end{tabular}

Figura 11. Comparación entre las unidades litoestratigráficas propuestas en el presente trabajo para la Cuenca Catalana y las unidades identificadas en la Cuenca Ibérica y en Mallorca. Las formaciones Sant Blai y Cardó de la Cuenca Catalana presentan más semejanzas con las unidades contemporáneas desarrolladas en Mallorca que con las de la Cuenca Ibérica. forme durante el Jurásico Medio. Teniendo en cuenta las diferentes facies dolomíticas de plataforma proximal desarrolladas en el Alto de El Maestrazgo, pueden distinguirse dos áreas: una interior, con secciones expandidas (100-250 $\mathrm{m})$; y otra periférica, con secciones condensadas (20-40 m) similares a las del Alto de Tarragona.

\section{Mallorca}

Junto a las diferencias faciales entre el Jurásico Medio de los Catalánides y el de la Cordillera Ibérica hay que señalar ciertas similitudes entre las unidades identificadas en los Catalánides y las unidades definidas en Mallorca (cf. Alvaro et al., 1989). En especial, la Fm. Calizas y calizas margosas de Sant Blai es contemporánea de la Fm. Margocalizas y calizas nodulosas de Gorg Blau (Fig. 11); del mismo modo, la Fm. Margas de Cardó es el equivalente cronológico de la Fm. Calizas y margocalizas de Cúber. Sin embargo, la Fm. Calizas y dolomías de La Tossa presenta notables diferencias de facies respecto a su equivalente temporal en Mallorca: la Fm. Calizas de Puig d'en Paré. Las semejanzas litoestratigráficas decrecientes entre estas sucesivas unidades litoestratigráficas

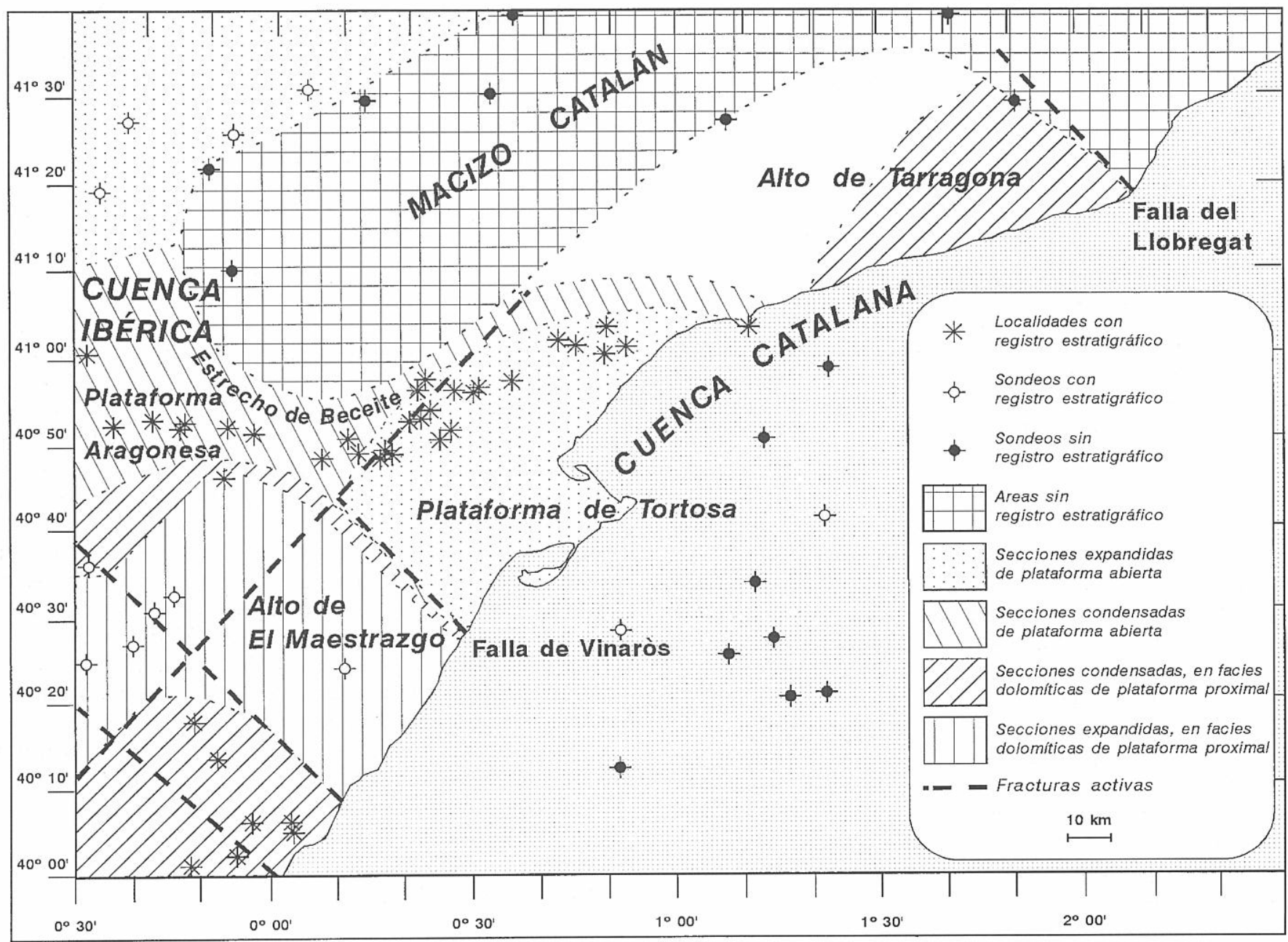

Figura 12. Principales elementos paleogeográficos durante el Jurásico Medio en la zona de entronque entre las cordilleras Costero-Catalana e Ibérica. Algunos límites de estos elementos paleogeográficos están controlados por fallas con orientaciones predominantes nordeste y sudeste. 
sugieren un paralelismo en la dinámica tectonosedimentaria de estos dos dominios, cada vez menor durante el Toarciense, Aaleniense y Bajociense, que se interrumpe a partir del Bathoniense inferior. No obstante, la escasez de ammonoideos leiostracos en la Cuenca Catalana contrasta con la frecuencia relativa que presentan en Mallorca (Alvaro et al., 1989; Sandoval, 1994) y es indicativa de que se trata de dos dominios geográficamente separados, con vías de dispersión biogeográfica y tafonómica diferentes.

\section{Principales sistemas de fracturas activas durante la sedimentación}

La configuración de estas diferentes áreas de sedimentación se enmarca dentro del régimen tectónico extensivo diferencial prácticamente generalizado en la Península Ibérica durante el Jurásico Medio. La Cuenca Catalana estuvo afectada por una serie de fracturas de diferente rango, que marcan algunos de los límites de los elementos paleogeográficos más significativos. Por ejemplo, el tránsito relativamente brusco entre el Alto de El Maestrazgo y la Plataforma de Tortosa sugiere que la articulación entre ambos elementos paleogeográficos estuvo controlada por una zona de fractura de orientación noroeste-sudeste (Fig. 12), a la que hemos denominado Falla de Vinaròs (Fernández-López et al., 1994). Con orientación subparalela a esta zona de falla existen otros accidentes a lo largo de la Cuenca Catalana, como por ejemplo la Falla del Llobregat (cf. Anadón et al., 1982; Llopis Lladó, 1943) próxima a Barcelona. También cabe destacar por su gran desarrollo longitudinal la falla que controla el límite sudeste del Macizo Catalán, cuya prolongación hacia el sudoeste condicionó la distribución de espesores y facies en el Alto de El Maestrazgo. Las variaciones de potencia y de distribución de facies de los materias del Jurásico Medio, desde los Puertos de Beceite hasta Cap de Salou, muestran un trazado arqueado que puede ser el resultado de un sistema de fallas, con trazado lístrico y con sentido descendente hacia el Mediterráneo, que debió controlar el límite noroeste de la Plataforma subsidente de Tortosa.

\section{CONCLUSIONES}

El análisis a escala zonal de los diferentes tipos de facies y de las pautas de distribución de las unidades litoestratigráficas permiten delimitar varios elementos paleogeográficos durante el Jurásico Medio, que debieron estar controlados tectónicamente y dieron lugar a la diferenciación de dos cuencas: la Cuenca Catalana y la Cuenca Ibérica, individualizadas por el Macizo Catalán y por el Alto de El Maestrazgo. Ambas cuencas estuvieron comunicadas entre sí a través del Estrecho de Beceite.

Dentro de la Cuenca Catalana destaca la Plataforma de Tortosa, afectada por una importante subsidencia que condicionó el desarrollo de secciones expandidas en facies de plataforma abierta especialmente durante los biocronos Niortense y Garantiana (Bajociense superior). Como en el resto de los elementos paleogeográficos de la Cuenca Catalana, las pautas de distribución de las facies del Jurásico Medio de la Plataforma de Tortosa estuvieron condicionadas por un sistema de fracturas activas durante la sedimentación.
Desde el punto de vista paleobiogeográfico destacan las semejanzas faunísticas que muestran las asociaciones registradas de ammonites respecto a las de otras cuencas epicontinentales europeas. Las máximas influencias mediterráneas ocurrieron durante el Biocrón Garantiana (Bajociense superior), cuando la cuenca alcanzó los máximos valores batimétricos y actuó como una área de expansión biogeográfica para algunos grupos taxonómicos característicos del Tethys occidental. Las litofacies del Toarciense superior, Aaleniense y Bajociense de la Cuenca Catalana presentan ciertas semejanzas con las desarrolladas en Mallorca; sin embargo, la diferencia en la proporción de ammonoideos filoceratáceos y litoceratáceos (abundantes en Mallorca y muy escasos en la Cuenca Catalana) es indicativo de que estas dos áreas estuvieron geográficamente aisladas una de otra y tuvieron vías de dispersión biogeográfica y tafonómica diferentes.

\section{AGRADECIMIENTOS}

Este trabajo es una contribución al proyecto PB92-0011 de la DGICYT. Los autores desean expresar su agradecimiento a los doctores J. Rosell Sanuy (Universidad Autónoma de Barcelona) y R. Salas (Universidad de Barcelona) por los comentarios y sugerencias realizadas respecto al manuscrito original del presente trabajo.

\section{BIBLIOGRAFÍA}

Alvaro, M., Barnolas, A., Cabra, P., Comas-Rengifo, M. J., Fernández-López, S., Goy, A., Del Olmo, P., Ramírez del Pozo, J., Simó, A. y Ureta, S. 1989. El Jurásico de Mallorca (Islas Baleares). Cuadernos de Geología Ibérica, 13, 67-120.

Anadón, P., Colombo, F., Esteban, M., Marzo, M., Robles, S., Santanach, P., y Solé Sugrañés, Ll. 1982. Evolución tectonoestratigráfica de los Catalánides. Acta Geológica Hispánica (Hom. L. Solé i Sabarís, 1979), 14, 242-270.

Aurell, M. 1990. El Jurásico superior en la Cordillera Ibérica Central (provincias de Zaragoza y Teruel). Análisis de cuenca. Tesis Doctoral, Departamento de Geología, Servicio de Publicaciones de la Universidad de Zaragoza, 510 pp.

Aurell, M., Meléndez, G. and Salas, R. 1990. The Oxfordian depositional sequence in the Central and Eastern Iberian Chain (NE Spain). Publicaciones del Seminario de Paleontología de la Universidad de Zaragoza, 2, 85-118.

Barale, G. y Calzada, S. 1985. Primera demostración paleontológica del Kimmeridgiense en Garraf (Barcelona). Acta Geológica Hispánica, 20, 227-231.

Barnolas, A., López Olmedo, F. y Simó, A. 1985. Jurásico. In: Memoria de la Hoja n. ${ }^{\circ}$ 496, E: 1/50.000, Horta de San Juan. IGME, 10-17.

Barnolas, A. y Simó, A. 1985. Jurásico. In: Memoria de la Hoja n. ${ }^{\circ}$ 521, E: $1 / 50.000$, Beceite. IGME, 8-16.

Bataller, J. R. 1922. El Jurásico de la Provincia de Tarragona. Trabajos del Museo Nacional de Ciencias Naturales, (Geol.), 29, 5-113.

Bataller, J. R. 1926. Sur le Jurassique de la partie méridionale de la Catalogne (Puertos de Tortosa). Bulletin de la Société Géologique de France, (4), 26: 101-116. 
Bulard, P. F. 1972. Le Jurassique moyen et supérieur de la Chaîne Ibérique, sur la bourdure du bassin de l'Ebre. Thèse Sci., Faculté des Sciences Physiques, Chimiques et Naturelles $\left(\mathrm{n}^{\circ}\right.$ CNRS: A.O. 7095), Université de Nice, 355 pp.

Burollet, P. F. et Winnock, E. 1977. Cartes sédimentologiques et paléogéographiques des régions périméditerranéennes occidentales. SPLIT-Yugoslavia (1976), 111-127. Technip, Paris.

Cadillac, H. 1979. Télédétection et Géologie. Essai d'utilisation des images Landsat dans les Pyrénnées, le Bassin de l'Ebre et la Catalogne. Tome II: Étude géologique dans les Ports de Horta de San Juan et Alfara (provinces de Tarragona et de Teruel, Espagne): corrélation avec le Tectolinéament de Tarragone à l'articulation entre Ibérides et Catalanides. Thèse doctoral, Faculté des Sciences, Université de Toulouse, 188 pp.

Cadillac, H., Canerot, J. et Faure, Ph. 1981. Le Jurassique inférieur aux confins des Ibérides et des Catalanides (Espagne). Estudios Geológicos, 37, 187-198.

Cadillac, H., Canerot, J. et Faure, Ph. 1985. Le Jurassique de l'anticlinal de Pauls. Strata, 2: 57-71.

Calzada, S. y Vía, L. 1971. Sobre el supuesto Jurásico del Macizo de Garraf (Barcelona). Cuadernos de Geología Ibérica, 2, 483-487.

Calvet, F.; March, M. y Pedrosa, A. 1987. Estratigrafía, sedimentología y diagénesis del Muschelkalk superior de los Catalánides. Cuadernos de Geología Ibérica, 11, 171-197.

Calvet, F.; Tucker, M. E. and Henton, J. M. 1990. Middle Triassic carbonate ramp systems in the Catalan Basin, northeast Spain: facies, systems tracs, sequences and controls. Special Publications of the International Association of Sedimento$\log y$, 9, 79-108.

Canerot, J. 1974. Recherches géologiques aux confins des Chaînes Ibérique et Catalane (Espagne). Thèse doctoral Université de Toulouse. Enadimsa ediciones, 4, 514 p.

Canerot, J. 1991. Comparative study of the Eastern Ibérides (Spain) and the Western Pyrenees (France) Mesozoic basins. Palaeogeography, Palaeoclimatology, Palaeoecology, 87, 1-28.

Canerot, J., Faure, Ph. et Rahal, M. 1984. Donnés nouvelles sur le Jurassique du Maestrazgo méridional (prov. de Castellón, Espagne). Comptes Rendues de l'Academie des Sciences de Paris, 298, 651-654.

Canerot, J., Faure, Ph. et Rahal, M. 1985. Le Jurassique réduit de la zone de transition du Maestrazgo méridional. Strata, 2, 85-100.

Cariou, E. 1987. Biostratigraphic subdivision of the Callovian stage in the Subtethyan province of ammonites. Correlations with the Subboreal zonal scheme. 1st. International Symposium on Jurassic Stratigraphy (1984), 315-326.

Cariou, E. and Meléndez, G. 1990. A modified perisphinctid zonation for the Middle Oxfordian of southern Europe, Submediterranean Province. 1st. Oxfordian Meeting. Publicaciones del Seminario de Paleontología de Zaragoza, 2, 129-151.

Choffat, P., 1880. Étude stratigraphique et paléontologique des terrains jurassiques du Portugal: Le Lias et le Dogger au Nord du Tage. Section des Travaux Géologiques du Portugal, 72 pp. Lisboa.

Dubar, G. 1925. Études sur les Lias des Pyrénées françaises. Mémoires de la Société Géologique du Nord, 9: 1-322.

Dubar, G. 1931. Brachiopodes liasiques de Catalogne et des régions voisines. Butlletí de la Institució Catalana d'Història Natural, 31, 103-180.
Elmi, S.; Goy, A.; Mouterde, R.; Rivas, P. y Rocha, R. 1989. Correlaciones bioestratigráficas en el Toarciense de la Península Ibérica. Cuadernos de Geología Ibérica, 13, 265-277.

Esteban, M. y Julià, R. 1973. Discordancias erosivas intrajurásicas en los Catalánides. Acta Geológica Hispánica, 8, 153-157.

Esteban, M. y Robles, S. 1979. Período preorogénico, el Mesozoico. Acta Geológica Hispánica, 11, 73-78.

Fallot, P. et Blanchet, F. 1923. Observations sur la faune des terrains Jurassiques de la région de Cardó et de Tortosa (Province de Tarragone). Treballs de la Institució Catalana d'Història Natural 6, 73-264.

Faura y Sans, M.; Fallot, P. et Bataller, J. R. 1921. Observations au sujet de la stratigraphie des terrains jurassiques de la chaîne de Cardó. Butlletí de la Institució Catalana d'Història Natural, $\mathbf{5}$ : 118-130.

Fernández-López, S. 1983. La Biozona Garantiana (Bajociense, Jurásico medio) en la región de Tivenys-Sierra de Cardó (Tarragona). Estudios Geológicos, 38 (1982), 75-93.

Fernández-López, S., 1985. El Bajociense en la Cordillera Ibérica. Tesis Doctoral, Departamento de Paleontología, Universidad Complutense, Madrid, 850 pp.

Fernández López, S. 1995. Taphonomie et intreprétation des paléoenvironnements. In M. Gayet y B. Courtinat (eds.): First European Palaeontological Congress, Lyon 1993. Geobios, M.S. 18: 137-154.

Fernández-López, S.; Aurell, M.; García Joral, F.; Gómez, J. J.; Henriques, M. H. P.; Martínez, G.; Meléndez, G. y Suárez Vega, L. C. 1994. La configuración paleogeográfica de la Cuenca Catalana durante el Jurásico Medio. Comunicaciones de las X Jornadas de Paleontología, 69-72.

Fernández López, S. y Gómez, J. J. 1991. Condensación: significados y aplicaciones al análisis de cuencas. Estudios Geológicos, 47, 169-181.

Fernández López, S. and Meléndez, G. 1994. Abrasion surfaces on inner moulds of ammonites as palaeobathymetric indicators. Palaeogeography, Palaeoclimatology, Palaeoecology, 110, 29-42.

Fernández-López, S. y Meléndez, G. 1995a. Dispersión biogeográfica y tafonómica de ammonoideos filoceratáceos hacia la Cuenca Ibérica durante el Jurásico Medio. Coloquios de Paleontología, 46 (1994): 129-149.

Fernández López, S. and Meléndez, G. 1995b. Taphonomic gradients in Middle Jurassic ammonites of the Iberian Range (Spain). In M. Gayet y B. Courtinat (eds.): First European Palaeontological Congress, Lyon 1993. Geobios, M.S. 18: 155-165.

Fernández-López, S. y Mouterde, R. 1985. Le Toarcien, l’Aalénien et le Bajocien dans le secteur de Tivenys: nouvelles donnés biostratigraphiques. Strata, 2, 71-88.

Fontana, B.; Gallego, M. R.; Jurado, M. J. and Meléndez, G. 1995. A correlation of subsurface and surface data of the MiddleUpper Jurassic between the Ebro Basin and the central Iberian Chain (Eastern Spain). Geobios, M.S., 17 (1994): 563-574.

García-Joral, F. y Goy, A. 1984. Características de la fauna de braquiópodos del Toarciense superior en el Sector Central de la Cordillera Ibérica (Noreste de España). Estudios Geológicos, 40, 55-59.

García-Joral, F. y Goy, A. 1994. Los braquiópodos del Toarciense de la Cordillera Ibérica. Comunicaciones de las X Jornadas de Paleontología, 81-83. 
Gautier, F. et Mouterde, R. 1964. Lacunes et irrégularités des dépôts à la limite du Jurassique inférieur et du Jurassique moyen de la bordure nord des Chaînes ibériques (Espagne). Comptes Rendus de l'Academie des Sciences Paris, 258, 3064-3067.

Giner, J. 1980. Estudio sedimentológico y diagenético de las facies carbonatadas del Jurásico de los Catalánides, Maestrazgo y Rama Aragonesa de la Cordillera Ibérica. Tesis doctoral, Departamento de Geología. Universidad de Barcelona, 315 pp.

Giner Sánchez, J. y Simó, A. 1985. Jurásico. In: Memoria de la Hoja n. ${ }^{\circ} 48$, E: 1/200.000, Vinarós, IGME, 21-29.

Giner Sánchez, J. y Simó, A. 1987. Jurásico. In: Memoria de la Hoja n. ${ }^{\circ} 42$, E: 1/200.000, Tarragona. IGME, 31-41.

Gómez, J. J. 1979. El Jurásico en facies carbonatadas del sector levantino de la Cordillera Ibérica. Seminarios de Estratigrafía (Serie Monografias), 4, 686 pp.

Gómez, J. J. y Fernández López, S. 1992. Secciones condensadas y máximos transgresivos. Una relación equívoca. Geogaceta, 11, 130-137.

Gómez, J. J. and Fernández López, S. 1994. Condensation processes in shallow platforms. Sedimentary Geology, 92, 147-159.

Gómez, J. J. y Goy, A. 1979. Las unidades litoestratigráficas del Jurásico medio y superior, en facies carbonatadas del sector levantino de la Cordillera Ibérica. Estudios Geológicos, 35, 569-598.

González, A. y Guimerà, J. 1993. Sedimentación sintectónica en una cuenca transportada por una lámina de cabalgamiento: la cubeta terciaria de Aliaga. Revista de la Sociedad Geológica de España, 6, 151-165.

Goy, A.; Gómez, J. J. y Yébenes, A. 1976. El Jurásico de la Rama Castellana de la Cordillera Ibérica (mitad norte): I. Unidades litoestratigráficas. Estudios Geológicos, 32, 391-423.
Guimerà, J. 1983. Evolution de la déformation alpine dans le NE de la Chaîne Ibérique et dans la Chaîne Côtière Catalane. Comptes Rendues de l'Academie des Sciences de Paris, 297, 425-430.

Guimerà, J. 1984. Paleogene evolution of deformation in the northeastern Iberian Peninsula. Geological Magazine, 121, 413-420.

Killian, W. et Fallot, P. 1920. Sur l'existence et les faciès de divers étages du Jurassique dans la Province de Tarragona. Comptes Rendues de l'Academie des Sciences de Paris, 171: 19-22.

Lanaja, J. M. 1987. Contribución de la exploración petrolífera al conocimiento de la Geología de España. Instituto Geológico y Minero de España, Madrid, 465 pp.

Llopis Lladó, N. 1943. Contribución al conocimiento de la morfoestructura de los Catalánides. Instituto Lucas Mallada, sección de Geomorfología (1947), Barcelona, 372 pp.

Losantos, M.; Aragonès, E.; Berástegui, X.; Palau, J. i Puigdefàbregas, C. 1989. Mapa geològic de Catalunya 1:250.000. Institut Cartogràfic de Catalunya.

Maldonado López, A.; Alonso Martínez, B.; Díaz Guerrero, J. I.; Ferrán Vert, M.; Giró Molner, S. y Vázquez Martínez, A. 1986. Mapa geológico de la plataforma continental española y zonas adyacentes. Escala 1:200.000, 41-42, Tortosa-Tarragona. IGME.

Marin, Ph., Pallard, B., Duval, B. y Miroschedji, A. de 1977. Jurásico. In: Memoria de la Hoja ${ }^{\circ}$ 494, E: 1/50.000, Calanda. IGME, 5-11.

Mateu Ibars, F. y Marzo, M. (eds.) 1985. Guía de la excursión Triásico de los Catalánides. Institut d'estudis ilerdencs, Lérida, $175 \mathrm{pp}$.

Meléndez, G., 1989. El Oxfordiense en el sector central de la Cordillera Ibérica (Provincias de Zaragoza y Teruel). Institución Fernando el Católico e Instituto de Estudios Turolenses, Zaragoza-Teruel, $418 \mathrm{pp}$.

\section{Lámina I}

1. "Trilobiticeras" cricki Parsons. Fragmocono con cámara de habitación, reelaborado. Ejemplar 36L5/2, x2. Llabería km 36. Cronorregistro Laeviuscula, Biozona Sauzei (Bajociense). $\mathrm{D}=11,8 ; \mathrm{H}=5,2$ (44,1); E= 7,1 (60,2); U= 4,0 (33,9); E/H= 136,5; $\mathrm{Ni} / 2=9 ; \mathrm{Ne} / 2=25$.

2. Mollistephanus hispaniensis Fdez.-López. Fragmocono incompleto, reelaborado. Ejemplar BR8/1, x2. Barranco de Romultá. Cronorregistro Laeviuscula, Biozona Sauzei (Bajociense). D= 21,0; H= 7,3 (34,7); E= 8,9 (42,4); U= 10,1 (48,1); E/H= 121,$9 ; \mathrm{Ne} / 2=34$.

3. Fontannesia sp. Fragmocono incompleto, reelaborado. Ejemplar 36L7/3, x1. Llabería km 36. Cronorregistro Discites o Laeviuscula, Biozona Sauzei (Bajociense). $\mathrm{D}=53,0 ; \mathrm{H}=21,5$ (40,6); E= 9,5 (17,9); $\mathrm{U}=18,1(34,2) ; \mathrm{E} / \mathrm{H}=44,2$.

4. Hildoceras sublevisoni Fucini. Fragmocono incompleto, reelaborado. Ejemplar 36L5/1, x1. Llabería km 36 . El flanco izquierdo ha sido limpiado (4A), eliminando una delgada costra ferruginosa con abundantes serpúlidos. En el flanco derecho (4B) se observa el encostramiento que recubre el molde interno del ammonites y una faceta elipsoidal de desgaste (FE) formada en las primeras fases de reelaboración en el último cuarto de espira conservada. Cronorregistro Serpentinus (Toarciense), Biozona Sauzei (Bajociense). D=77,0; H= 23,4 (30,4); E= 15,4 (20,0); U= 35,1 (45,6); E/H= 65,8; Ne/2=15.

5. Abbasitoides modestus (Vacek). Fragmocono incompleto, reelaborado. Ejemplar 36L4c/2, x1. Llabería km 36. Cronorregistro Murchisonae o Bradfordensis, Biozona Bradfordensis (Aaleniense). $\mathrm{D}=37,0 ; \mathrm{H}=11,0(29,7) ; \mathrm{E}=12,8(34,6) ; \mathrm{U}=16,3$ $(44,1) ; \mathrm{E} / \mathrm{H}=116,4 ; \mathrm{Ni} / 2=23$.

6. Erycites cf. fallifax Arkell. Fragmocono incompleto, resedimentado. Ejemplar 36L4c/1, x1. Llabería km 36. Biozona Bradfordensis (Aaleniense).

7. Welschia sp. Fragmento de cámara de habitación, resedimentado. Ejemplar 36L4c/5, x1. Llabería km 36. Biozona Bradfordensis (Aaleniense).

8. Brasilia deleta (Buckman). Fragmocono con cámara de habitación, resedimentado. Ejemplar 36L4c/4, x1. Llabería km 36. Biozona Bradfordensis (Aaleniense). $\mathrm{D}=44,0 ; \mathrm{H}=20,4$ (46,4); $\mathrm{E}=8,9$ (20,2); $\mathrm{U}=10,2$ (23,2); $\mathrm{E} / \mathrm{H}=43,6$.

9. Brasilia bradfordensis (Buckman). Fragmocono con cámara de habitación, resedimentado. Ejemplar 36L4c/3, x1. Llabería km 36. Biozona Bradfordensis (Aaleniense). $\mathrm{D}=36,7 ; \mathrm{H}=17,8(48,5) ; \mathrm{E}=9,0(24,5) ; \mathrm{U}=8,6(23,4) ; \mathrm{E} / \mathrm{H}=50,6 ; \mathrm{Ne} / 2=26$.

La flecha indica el límite entre la cámara de habitación y el fragmocono. 
Lámina I
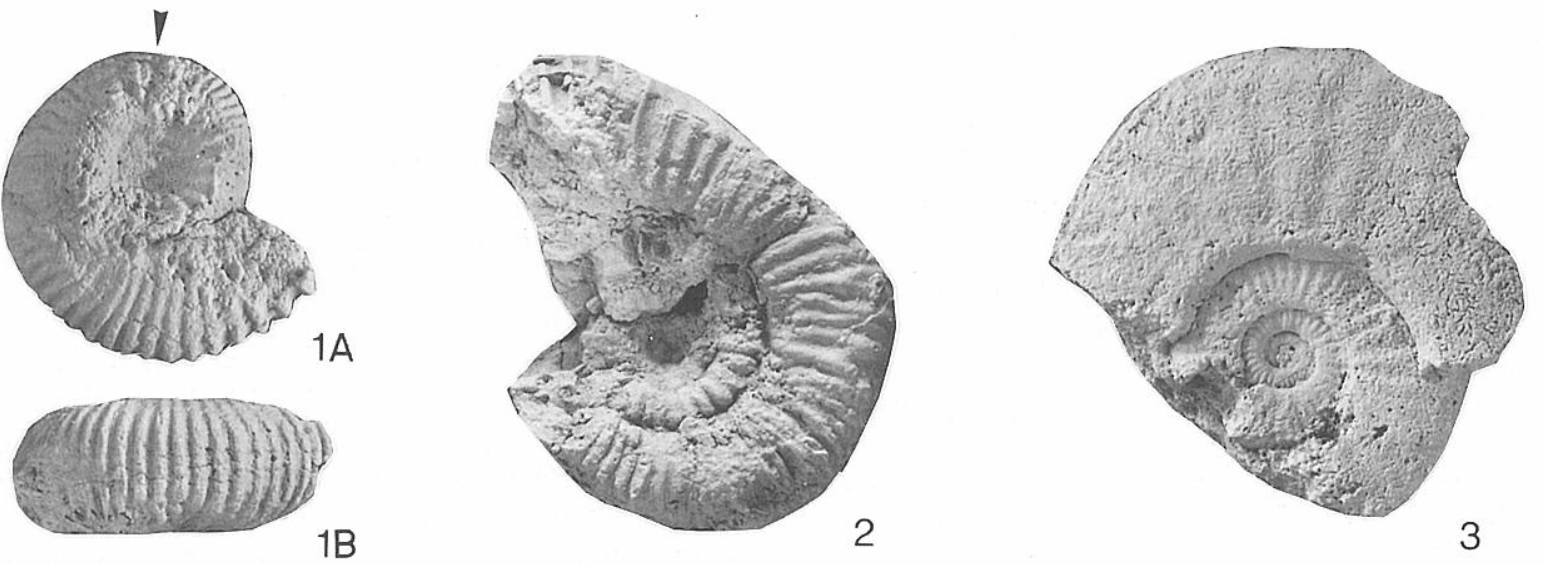

$1 \mathrm{~B}$
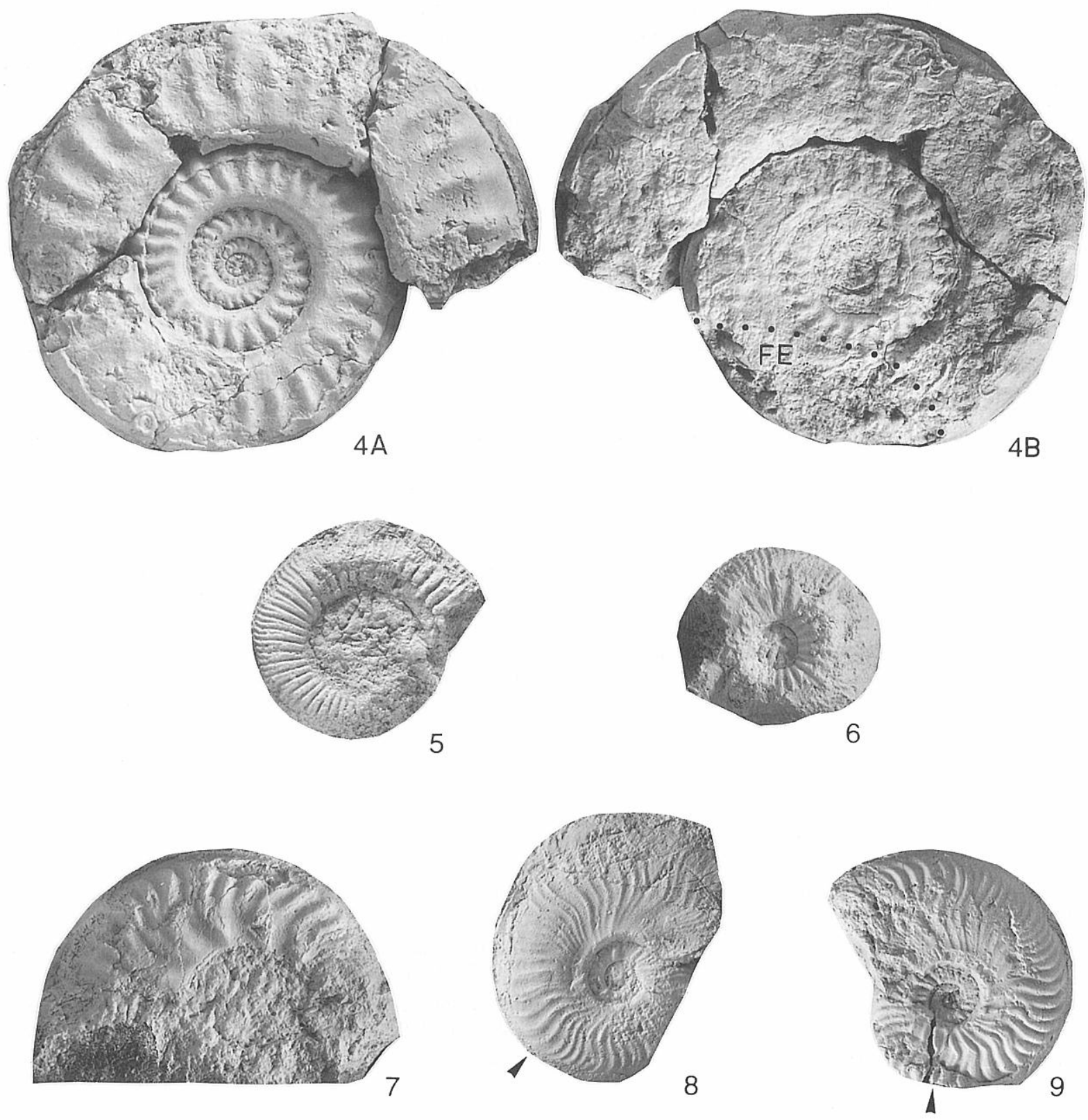
Núñez, A., Colodrón, I. y Ruiz, V. 1980. Jurásico. In: Memoria de la Hoja n. ${ }^{\circ}$ 472, E: 1/50.000, Reus. IGME, 7-12.

Orche, E., Robles, S. y Rosell, J. 1980a. Jurásico. In: Memoria de la Hoja n. ${ }^{\circ}$ 471, E: 1/50.000, Mora de Ebro. IGME, 11-15.

Orche, E., Robles, S. y Rosell, J. 1980b. Jurásico. In: Memoria de la Hoja n. ${ }^{\circ}$ 497, E: 1/50.000, Perelló. IGME, 7-12.

Robles Orozco, S. 1974. Estudio geológico del Mesozoico del Macizo del Cardó y sectores adyacentes. Tesis doctoral, Universitat Autonoma de Barcelona, 436 pp.

Robles Orozco, S. 1975. Síntesis de la evolución estratigráfica y tectónica de los materiales secundarios del bloque del Cardó y sectores adyacentes (provincia de Tarragona). Acta Geológica Hispánica, 10, 59-66.

Roca, E.; Guimerà, J. and Salas, R. 1994. Mesozoic extensional tectonics in the southeast Iberian Chain. Geological Magazine, 131: $155-168$

Rosell Sanuy, J. y Vía Boada, L. 1967. Estudio geológico de los alrededores de Beceite (Teruel). Notas y Comunicaciones del IGME, 101-102, 5-20.

Salas, R. 1987. El Malm i el Cretaci inferior entre el Massis de Garraf i la Serra d'Espadá. Analisi de conca. Tesis doctoral Universitat de Barcelona, Departament de Geoquímica, Petrología i Prospecció geológica, 354 pp.
Salas, R. 1989. Evolución estratigráfica secuencial y tipos de plataformas de carbonatos del intervalo Oxfordiense-Berriasiense en las Cordilleras ibéricas oriental y costero-catalana. Cuadernos de Geología Ibérica, 13, 121-157.

Salas, R. 1991. Evolución de la Cuenca del Maestrat durante el Malm y el Neocomiense. Guía de Campo, Universitat de Barcelona: $118 \mathrm{pp}$.

Salas, R. and Casas, A. 1993. Mesozoic extensional tectonics, stratigraphy and crustal evolution during the Alpine cycle of the eastern Iberian basin. Tectonophysics, 228, 33-55.

Sandoval, J. 1994. The Bajocian stage in Island of Mallorca: biostratigraphy and ammonite assemblages. Miscellanea del Servizio Geologico Nazionale, 5, 203-216.

Simó, A. 1985. Jurásico. In: Memoria de la Hoja n. ${ }^{\circ}$ 496, E: 1/50.000, Horta de San Juan. IGME, 10-17.

Stoeckinger, W. T. 1976. Valencian gulf offer deadline nears. The Oil and Gas Journal, 29, 197-204.

Wilde, S. 1988. Das Bathonium und Callovium der nordwest-iberischen Ketten (Jura, Spanien). Bochumer Geologische und Geotechnische Arbeiten, 31, 1-217.

Manuscrito recibido: 24 de enero, 1995 Manuscrito aceptado: 20 de octubre, 1995 